\title{
Mortars and plasters-how to manage mortars and plasters conservation
}

\author{
Marta Caroselli ${ }^{1}\left[\right.$ - Silvestro A. Ruffolo ${ }^{2}\left[\right.$. Francesca Piqué ${ }^{1}[$
}

Received: 8 February 2021 / Accepted: 30 June 2021 / Published online: 13 October 2021

(c) The Author(s) 2021

\begin{abstract}
The use of mortars and plasters has been widespread in many cultures for thousands of years and these materials are found in the vast majority of built cultural heritage. They play a crucial role in the preservation of immovable heritage and must be taken into great consideration when conserving historical buildings. Plasters and mortars have been extensively studied from a chemical and mineralogical point of view. The main causes and mechanisms of damage and deterioration are understood and various methods and materials have been developed for their preservation. Treatment development, testing and evaluation in the laboratory, under controlled conditions, has produced a high level of knowledge. However, there is a divergence between the results of academic-scientific studies and practice in the field. Laboratory studies typically tackle only a few variables at the time and the results cannot always be directly applied to address the complex problems that restorers face in their daily work practice. In addition, in situ conservation-restoration is extremely challenging because many of large number of variables involved cannot be controlled or modified. Following a description of the ideal "value-based" conservation process, this compilation work discusses aspects related to understanding deterioration mechanisms and planning of preventive and remedial interventions in a way that may be useful to update conservators-restorers on the status of scientific research in this field, and to guide conservation-scientists to identify unresolved issues, which require future research efforts.
\end{abstract}

Keywords Mortar $\cdot$ Plaster $\cdot$ Conservation $\cdot$ Interventions $\cdot$ Salts removal $\cdot$ Consolidation $\cdot$ Restoration $\cdot$ Preventive conservation $\cdot$ Maintenance

\section{Premise}

This Topical Collection (TC) covers several topics in the field of study, in which ancient architecture, art history, archaeology, and material analyses intersect. The chosen perspective

This article is part of the Topical Collection on Mortars, plasters and pigments: Research questions and answers

Marta Caroselli

marta.caroselli@supsi.ch

Silvestro A. Ruffolo

silvestro.ruffolo@unical.it

Francesca Piqué

francesca.pique@supsi.ch

1 Institute of Materials and Construction (IMC), Department of Environment Construction and Design (DACD), University of Applied Sciences and Arts of Southern Switzerland (SUPSI), Mendrisio, Switzerland

2 Department of Biology, Ecology and Earth Sciences (DiBEST), Calabria University, Rende, Italy is that of a multidisciplinary scenario, capable of combining, integrating, and solving the research issues raised by the study of mortars, plasters, and pigments (Gliozzo et al. 2021). The first group of contributions explains how mortars have been made and used through the ages (Arizzi and Cultrone 2021, Ergenç et al. 2021, Lancaster 2021, Vitti 2021). An insight into their production, transport and on-site organizsation is further provided by DeLaine (2021). Furthermore, several issues concerning the degradation and conservation of mortars and plasters are addressed from practical and technical standpoints (this paper, La Russa and Ruffolo 2021). The second group of contributions is focused on pigments, starting from a philological essay on terminology (Becker 2021). Three archaeological reviews on prehistoric (Domingo Sanz and Chieli 2021), Roman (Salvadori and Sbrolli 2021), and Medieval (Murat 2021) wall paintings clarify the archaeological framework. A series of archaeometric reviews illustrate the state of the art of the studies carried out on Fe-based red, yellow, and brown ochres (Mastrotheodoros et al. forthcoming);, Cu-based greens and blues (Švarcová et al. 2021); 
As-based yellows and reds (Gliozzo and Burgio 2021); lead-based whites, reds, yellows, and oranges (Gliozzo and Ionescu 2021);, Hg-based red and white (Gliozzo 2021); and organic pigments (Aceto 2021). An overview of the use of inks, pigments, and dyes in manuscripts (Burgio 2021) and on glass-based pigments (Cavallo and Riccardi forthcoming) is also presented. Furthermore, two papers on cosmetic (Pérez Arantegui 2021) and medicinal pigments (Knapp et al. 2021) provide insights into the variety and different uses of these materials

\section{Introduction}

The conservation of ancient material is one of the founding activities of a modern society because cultural heritage is the irreplaceable and precious testimony of our past (Mason and Avrami, 2002). The task of those involved in conservation is to identify and preserve the cultural significance of an object for present and future generations, recognizing an esthetic, historical, scientific, spiritual, or social value, of which works of art are the expression (Avrami et al. 2019). The Burra Charter describes the conservation process and its achievement through a methodological process that starts by identifying and describing the cultural significance and continues through an evaluation of the constraints and the opportunities provided by its preservation (The Burra Charter, 2013).

The purpose of this work is to analyze the state of the art concerning the conservation of a specific class of material: mortars and plasters. Often the term mortar is used to refer to both plasters and mortars; however, mortars are used in masonry for joining stones, bricks, blocks etc. while plasters are used for rendering on the outside and inside of walls. By using the terms "mortars and plasters," we are here referring to a generic artificial stone material, made of binder and aggregates, used in masonries as a bedding mortar or for protection (e.g., render and plaster) but including also decorative mortars (for specific definition see: UNI 1092, 2001; EN 16572, 2015). Instead, this paper does not cover wall paintings, i.e., plasters with paint layers. However, several of the research results and concepts discussed in this article can be applied to wall paintings and painted plasters. Mortars and plasters have been used for thousands of years and are an integral part of the cultural heritage built in masonry (Hughes et al. 2012). They tell the story of artisan production, workforces, culture, and technology development. Preserving this class of material does not only mean preserving their visual appearance, but also conserving the textural characteristics and the material components (binder and aggregates).

In this article, the term "conservation" is used to indicate measures and actions aimed at safeguarding tangible cultural heritage, and includes preventive, remedial, and restoration interventions. Remedial interventions are the actions directly applied to the object, typically to strengthen it, while preventive interventions are those applied to modify the surrounding environment and to reduce the causes and mechanisms of deterioration. The word "restoration" indicates actions aimed at improve readability and transmission of the object's message (ICOM-CC, 2021 website, terminology of conservation; Viñas, 2002).

Immovable heritage is characterized by heterogeneity and vast surfaces. In mortars and plasters, the heterogeneity can be due to differences in the composition, in the technical execution and/or to different exposure to environment and other deterioration factors (including previous interventions). The problems and the behavior of mortars and plasters can vary from one point to the other and requires accurate assessment (Fig. 1). Immovable heritage is typically exposed to the climate and the environmental factors, such as temperature and humidity, which play a fundamental role in the deterioration causes and/or mechanisms. Mortars and plasters, as directly connected to supporting structures of one building, constitute the interphase between the physical heritage and the climate in an open physical system. This system, composed of the building and its surrounding climate, can rarely be modified to prevent deterioration. Therefore, conservation of immovable heritage is challenging because of its size, its heterogeneity, the complexity of diagnostic investigations,
Fig. 1 Casa Zuccarelli, Ticino $(\mathrm{CH})$. Examples of a decorated facade. On the left the general view of the deteriorated plaster; on the right a detail of the graffito, representing a loggia of the same façade during the conservation works
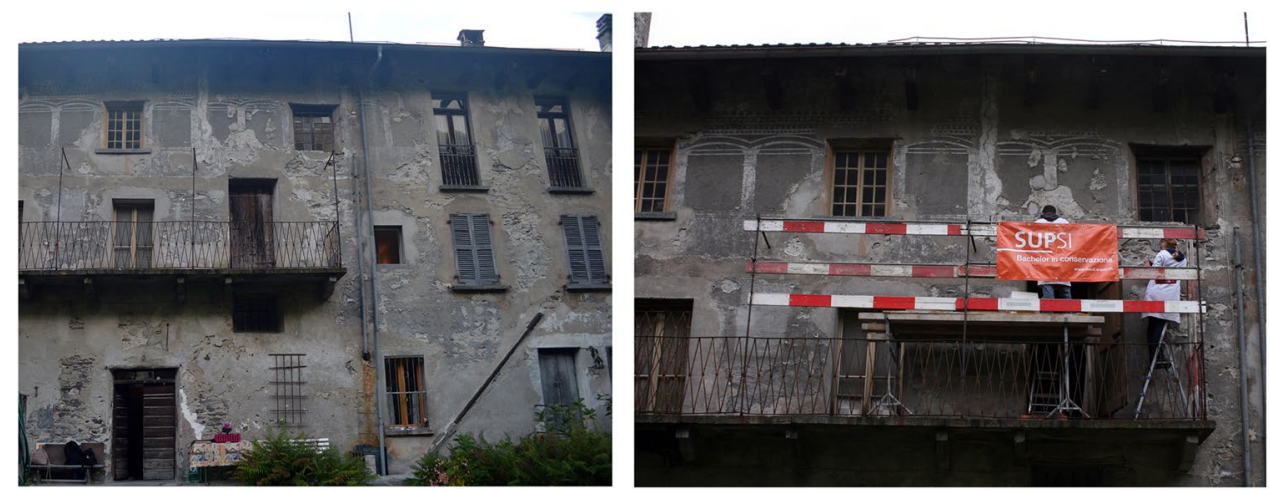
and to the intrinsic limits of preventive actions. Even if completely understood, the causes and mechanisms of deterioration can rarely be resolved and therefore it is fundamental to establish regular controls and maintenance operations to provide care over time. All of these issues, common to build heritage, justify the need of multidisciplinary teams (conservators, engineers, chemists, biologists, geologists, architects, art-historians, etc.) to plan and implement an effective and long-last conservation program.

\section{Description of the article's structure and content}

In "The conservation process," this article discusses the conservation process, i.e., the decision-making mechanism focusing on specific aspects of the conservation of mortars and plasters. As so eloquently described by Sharon Cather when talking about conservation, the most effective way to act is to address (and remove/reduce) the causes and mechanisms of deterioration, in addition to strengthening the object. Consolidation, adhesion, and fixing alone will not last when deterioration is still ongoing. To achieve this, is fundamental to understand, hopefully mitigate and slow down the harmful deterioration processes (Cather 2003b).

The section "The interventions" of the article describes the state of the art of interventions starting with some examples of preventive and passivating measures ("Preventive conservation") and then discussing direct interventions ("Direct interventions"). These are organized in subsections: interventions aimed at removing harmful materials ("Removal of harmful material"), i.e., soluble salts ("Soluble salts") and biodeteriogens ("Actions against biodeterioration") and interventions which add new materials ("The addition of new materials"), i.e.,consolidation ("Consolidation treatments"), grouting ("Injection grout"). Finally, interventions that aim at replacing mortars and plasters when they are too damaged or missing (25). Each intervention is defined (Definition of the intervention) and the most important critical aspects (critical issues) are discussed. The state of the art of the single operation is presented taking in consideration the most common materials and methods with some examples (Material and methods: case studies). Furthermore, requirements and criteria for the intervention are highlighted (Requirements and criteria) together with methods for intervention evaluation (Evaluation of treatments).

\section{The conservation process}

In the twenty-first century, conservation must be seen as part of an on-going process (rather than a single operation) to manage immovable cultural heritage over time. In this modern approach, the aim is to preserve the significance of the object which need identification and agreement by all stakeholders involved in management and conservation.

This is the so called "value-based approach" (The Burra Charter, 2013), that guides the decisions making process by identifying urgencies and priorities. The direct intervention on the object is only one phase of this process and not the end-point (Fig. 2). The evaluation of the object provides information on its significance, how it is made, what are the problems and the climatic context. These are key data to guide choices for safeguard. In practice, when we focus on mortars and plasters, identifying the values and the characteristics of the ancient material is as important as organizing these values attributing priority in the event of a conflict. An artistic and esthetic value can be easily associated if a plaster surface is decorated, but mortars and plasters embody also the material witnesses of a past environment, of a history of technology and use, i.e., a scientific value with high potential for research (as described in other chapters of the book). Above all, mortars and plasters have to fulfill fundamental functional roles through properties, such as porosity, mechanical resistance, adhesion, elastic module, water, and vapor transmission. This functional aspect is often a key element in the decision process: keep and preserve or replace an existing mortar or plaster. The delicate balance to be pursued is between the conservation of the material as it is, without substantially altering its nature, and the possibility of guaranteeing adequate physical-mechanical properties compatible with the long-term survival of the object. Therefore, the condition of each mortar and plaster element must

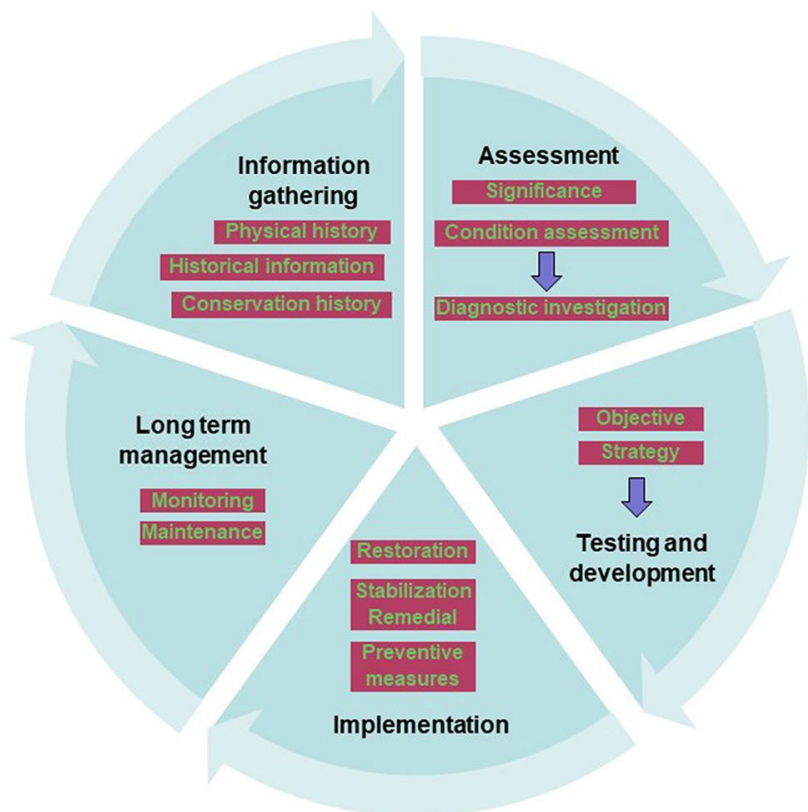

Fig. 2 Summary scheme of the conservation process, modifying the one proposed by Piqué et al 2010 
be determined case by case to choose whether it is possible to keep it or it is necessary to replace it. The willingness to maintain a compromised material at the price of completely changing its nature (and therefore losing part of its significance) makes little sense and often requires a large amount of resources.

If the replacement decision is taken, i.e., the functional and protection role of the plaster overtakes the scientific and historical one, it is important to ensure the maintenance of good size testimonial portions, ideally on site, perhaps in a protected area. If this is not possible, large fragments should be saved and archived for future references. If instead the decision is to keep the material, it is necessary to understand the information needed for its preliminary characterization (Ergenç et al. 2021). For these composite materials, it is necessary to characterize the main components, such as binder and aggregate, additives and texture (information gathering, in Fig. 2). This needs sampling and petrographic analysis on small representative sound samples. This analysis requires minimal time and resources and allows to identify with good approximation also the presence of potentially problematic elements (clay, low binder content, secondary products, micro-cracks, etc.), providing information for the subsequent diagnostic phase (Hughes and Válek, 2003; Elsen, 2006; Lugli et al. 2016; Hughes, 2017). Petrographic analysis is non-destructive since the thin sections remain for other types of investigations such as micro-FT-IR, micro-Raman, and SEM-EDS. Similarly, chemical-mineralogical analyzes often performed on powdered mortars (i.e., XRD, FT-IR, XRF) are non-destructive and samples should be saved and archived for further study. Physical and mechanical properties are of great importance, but their standard measurement requires large sample size and this is not often feasible on cultural heritage (Valek and Veiga, 2005). Fortunately, petrographic analysis permits a rough estimation of some of the mortar's physical and mechanical properties, such as nature and distribution of porosity.

Following characterization of the material, the conservation process (assessment, in Fig. 2) tackles condition and environmental assessment. This moment is the fundamental prerequisite for understanding the causes and mechanisms of deterioration (Demas, 2002; La Russa and Ruffolo, 2021). It is important to distinguish damage from deterioration and to describe their distribution. There are European standards that specify the requirements for a condition survey stating how an immovable cultural heritage object should be registered, examined, documented and reported on (EN 16,096 _ Conservation of cultural property - Condition survey of immovable cultural heritage 2012).

The planning phase (testing and development, in Fig. 2) follows the assessment and is the most challenging. In fact, in a very schematic way, Arnold's hierarchy (Arnold, 1996) is organized on the basis of the effectiveness of action against harmful changes (i.e., deterioration). It is much more effective to act on the causes and mechanisms of deterioration than to deal only with the symptoms by strengthening the object, i.e., remedial intervention (Cather 2003b). However, it is often difficult to completely understand the mechanisms of deterioration through a diagnostic process because of complex phenomena and multiple causes. Their effects can be entangled in such a way that the data available to scientists are generally insufficient (Torraca, 1999). In addition, for immovable heritage, such as buildings and their mortars and plasters, both the removal of the causes of deterioration and/or reduction of the deterioration mechanisms through environmental conditioning are rarely possible. For example, in Fig. 3, it is clear that the cause of water damp cannot be removed, because the building is located on the banks of the Po River and thus it suffers periodic flooding.

If the assessment phase has highlighted an imminent risk of loss of material, it will be necessary to intervene with a conservative stabilization treatment. Only after having stabilized the cause of the deterioration and the object itself, it could be possible to restore it, to improve its readability (Implementation in Fig. 2). The idea here is to search for the right compromise choosing the lesser of two evils, aware of all the issues we were not able to clarify. Knowing the limits of the intervention is important as it highlights the dangerous unresolved deterioration processes and the most fragile areas to control and to maintain over time.

After setting the objectives of the intervention (what do we want to do?), it is possible to choose among the possible options available, defining a strategy (how do we want to act?) regarding the methods and the materials of the technical operations. For each intervention, based on the objectives

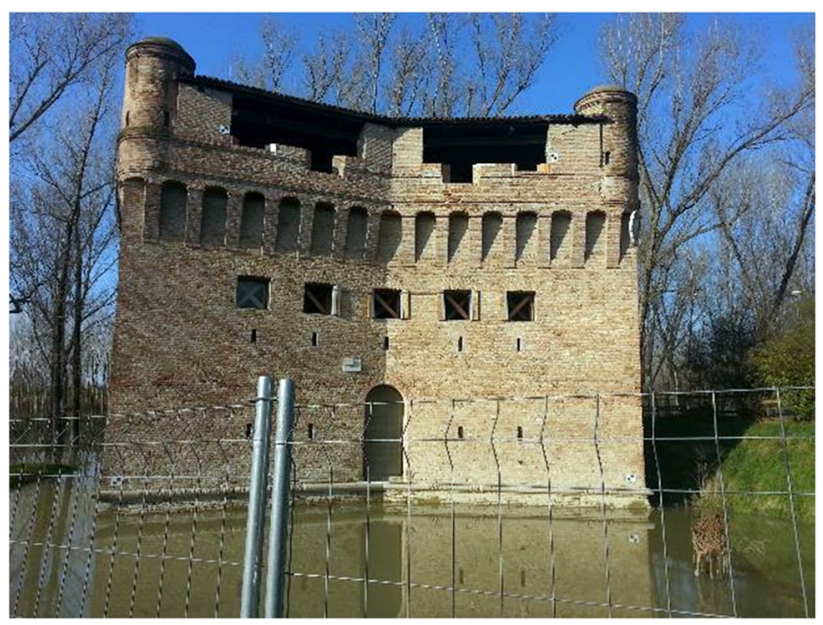

Fig. 3 The "Rocca Possente" situated in Bondeno, province of Ferrara (IT). Due to its location on the banks of the Po river, this building suffers periodic flooding and problems related to liquid water and capillary rise 
set for conservation, long-term performance criteria and working properties of the materials must be established.

While the interventions of the implementation phase will be discussed in "The interventions," it is important to highlight the need for planning maintenance. In fact, maintenance is the on-going process of preventive actions specifically developed to slow down the deterioration rate and sustain an object in an appropriate condition (to retain its significance). Control and monitoring is essential to check the evolution of a place and to verify that the measures taken are correct (long-term management, in Fig. 2). We must be aware that the perfect project does not exist and that periodic reviews are therefore necessary (Demas, 2002). Finally, the management of the site has to be implemented consistently with the choices made (Mackay, 2019).

The continuously evolving results of the conservation process are an archive which contains the information deriving from preliminary studies, direct observations, treatments, and on-going monitoring and maintenance. Evolving information technology offers new possibilities for recording and managing information but, at the same time, they require specific resources and expertise such as graphic designers, video makers, and computer specialists (AA.VV. 1999; Russo et al. 2020). The collected data should be made available for everyone. The Internet and Open data publication increases the possibility for sharing experiences, results and best practices.

\section{The interventions}

This part of the paper will review both direct and indirect interventions on mortars and plasters. As the name suggests, direct interventions are actions on the material (such as cleaning, consolidation, reestablishment of adhesion) while indirect interventions are those aimed at improving the condition surrounding the object to remove or reduce the causes and/or the mechanisms of deterioration and are often associated with preventive conservation. These actions are usually not directed to mortars and plasters, but at the building as a whole.

\section{Preventive conservation}

Good site and conservation management includes indirect measures such as regular controls and maintenance operations, and basic action such as avoiding spreading de-icing salts in the surrounding of the building (Fig. 4). In the case of mortars and plasters, the most common processes of deterioration are connected with the presence of water, in solid, liquid, and gas physical state. Calcareous mortars can be particularly susceptible to damage, especially if the water is acid (e.g., due to pollutants). Furthermore,

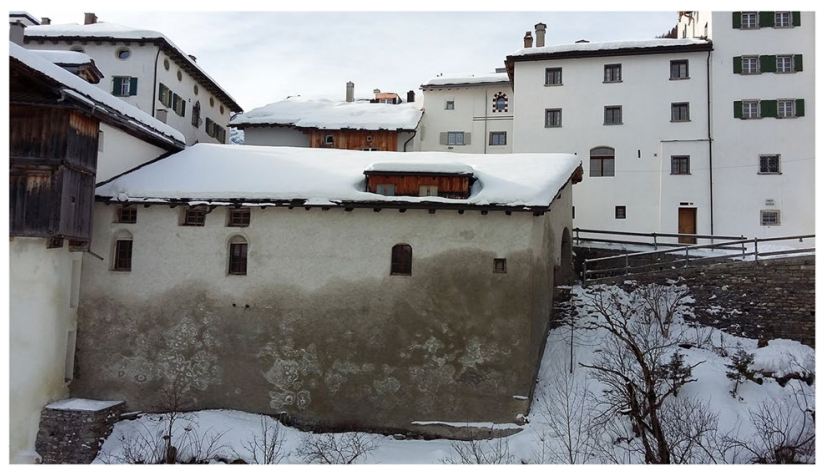

Fig. 4 Example of snow accumulation around a building, as a source of water and soluble salts. Splugen, $\mathrm{CH}$

important mechanical stresses can be induced through freeze-and-thaw cycles and expansion of clay-containing materials. In addition, water is an excellent transport medium for soluble salts and therefore it is the activating agent for basically all deterioration linked to the presence of salts, particularly in case of crystallization and dissolution cycles (Torraca 2009; Arnold and Zehnder, 1991; Matteini 1991). Moreover, the presence of water supports biodeterioration as it provides the necessary moisture for biocolonization (Caneva et al. 2009; Charola and Wendler 2015). For these reasons, understanding the ways water reaches and moves within the porous structure of a given material (Fig. 5) is essential to clarify the deterioration mechanisms (Petković et al. 2007).

To act on the deterioration mechanism created by salts means to prevent the further entry of salts and/or humidity, identifying their respective sources and determining whether they are active (Lubelli et al. 2004; Blaeuer and Rousset, 2014). If the source is still active, it is necessary to correctly address the cause, and only afterwards, it will be possible to decide whether to remove the salts already present. Consequently, preventive measures are often aimed at reducing the introduction of water. Methods for rising damp removal are reviewed in Franzoni (2014).

When hygroscopic salts are present, preventive measures, such as environmental control, are fundamental. For example, in the case of the desert site of Mogao in China, preventive measures include closing the cave during periods of high external humidity to avoid the intrusion of humid air into the cave. This measure maintains stable relative humidity conditions (Agnew and Wong, 2014). In other cases, the best option may be to keep the relative humidity high to prevent crystallization of the hygroscopic salts, see for example the case of Crypt in Valletta, Malta (Tringham et al. 2013). Indirect actions aimed at environmental modification for immovable heritage are extremely challenging and require careful planning, implementation in steps and regular control. 
Fig. 5 Processes responsible for water in porous building materials

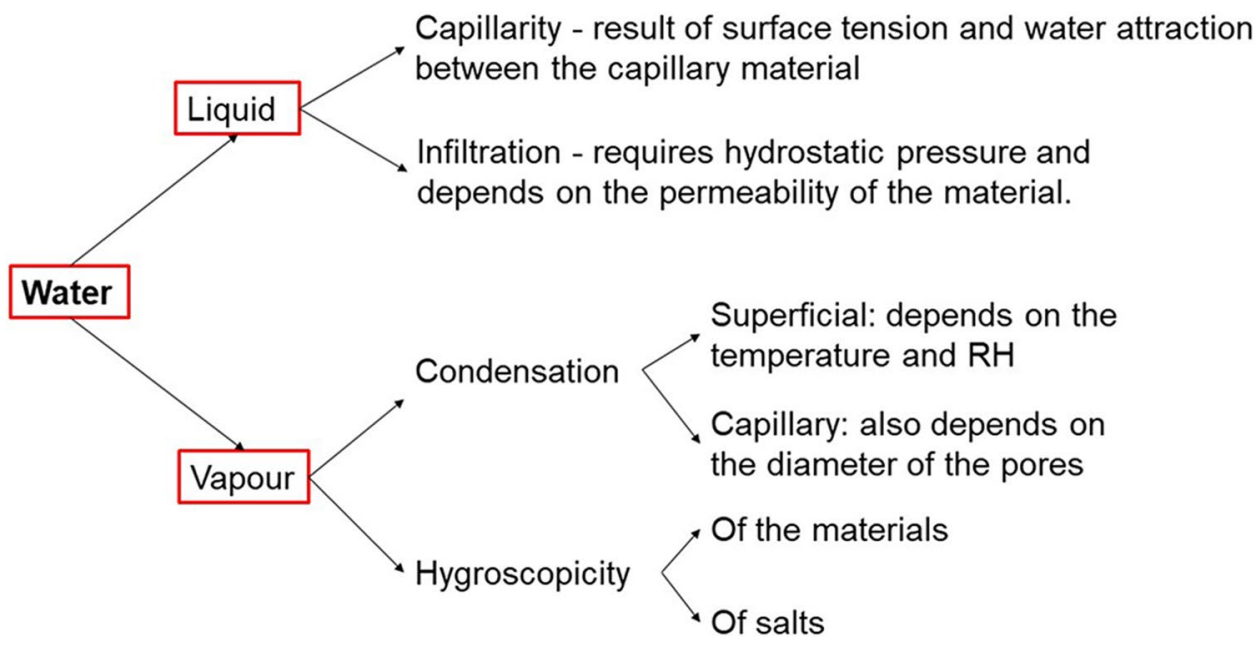

Preventive actions are the most effective and economical and can virtuously involve employees and users, but for the same reasons, they can hardly be guaranteed in the long term. Among the preventive treatments, periodic maintenance operations are also considered, such as roof control, water drainage, structural repairs, and downspouts. The deterioration speed of mortars and plasters depends on the efficiency of the systems that protect the building from water: roofs, sheaths, sloping ceilings, cornices, frames, drains, etc. (Camuffo, 2019). Building lack of maintenance is very often the main problem and causes severe deterioration mechanisms (Caroselli et al. 2019). Therefore, careful and regular maintenance is the best method for conservation.

\section{Direct interventions}

The development of a direct intervention includes the definition of the objectives and of the most appropriate materials and methods to carry it out. Naturally, as discussed above, the planning begins with a good analysis of the problem that needs to be stabilized, but also, in the case of on-going deterioration, from the level of reduction of the causes and mechanisms of deterioration responsible for the problem. On the basis of these factors, the objectives and criteria for intervention are defined (Tringham and Rickerby, 2020; Cather 2006).

Before starting any direct intervention that involves "touching" the surface, it is necessary to evaluate the need for pre-consolidation to stabilize the surface sufficiently enough so that operations can be carried out without the risk of losing original material. Pre-consolidation involved preliminary repair of the damage created over time, e.g., disaggregation or detachment. The materials that could be used for this purpose are discussed in the sub-chapter adhesion and consolidation, but they must be selected to be compatible with the treatments that will follow.

\section{Removal of harmful material}

Removal of harmful material could be seen as a specific operation within the more general term "Cleaning" and it is aimed at removing unwanted non-original materials. The process of removing something from a work of art is irreversible by definition and therefore needs an extremely clear motivation. The idea behind this operation is to selectively eliminate the foreign materials causing and/or deriving from deterioration, without altering the original substrate but leaving uncontaminated what is part of the history of the artwork. This paper will focus only on the presence of soluble salts and biological colonization, because they are the two most dangerous and widespread categories of contaminants for mortars and plasters.

\section{Soluble salts}

Definition of the intervention Salt removal directly seeks to eliminate or reduce the amount of soluble salts present in a substrate. The options available for the removal of salts essentially fall into one of three categories: (i) mechanical removal of salts in crystalline form, e.g., brushing off efflorescence; (ii) dissolution and extraction of ions in solution with poultices; and (ii) electrochemical method with anode and cathode. For the second and third category, the transport mechanism of saline solutions plays a fundamental role (Zezza, 2010).

Critical issues The intrinsic difficulties related to the attempts at removing soluble salts in solution from porous materials are well known (Cather, 2003a), and it is therefore more correct to talk about reduction of salts rather than "salt-removal." The success of salt reduction treatments depends on several factors, such as salt distribution, the transport processes involved, and the climatic context of 
the object (Sawdy et al. 2008; Pel et al. 2010). These are all complex aspects and their understanding requires significant resources (time and money) as well as expertise. The evaluation of the presence of salts before and after the reduction intervention involves invasive investigations (micro-core sampling) and is often not possible. As a consequence, salt reduction attempts are carried out without proper evaluation, "hoping for the best," and the real effects may be evident only over time. Therefore, the effectiveness of these treatments requires long-term monitoring (Sawdy et al. 2010).

Materials and methods: case studies Conservation treatments aim at reducing salt content from the substrate (mechanically, physico-chemically or electrochemically) and, given the difficulties in planning, implementing, and maintaining preventive measures related to environmental control, the reduction methods are by far the most used. The mechanical removal of efflorescence (if applicable) is undoubtedly the simplest and most effective method, which only requires great care to avoid further surface damage.

The electrochemical method with anode and cathode is also very effective in theory in the extraction of soluble salts, despite being a complicated process that requires very specialized personnel. However, there is the risk, if the system stops for some reason, that it can produce much worse consequences. Furthermore, the material acidifies around the anode and around the cathode it becomes alkaline, leading to extreme changes in $\mathrm{pH}$ due to water hydrolysis. These extreme $\mathrm{pH}$ values can lead to chemical alteration of the materials (Ottosen et al. 2007; Feijoo et al. 2018).

Extractive poultices are the most studied treatment in this context, because they have shown efficacy in reducing salts and are relatively easy to carry out. However, their success is variable because the new salt system created is unpredictable and the most critical problem is the further diffusion of salts as ions in solution into the non-contaminated portions of the masonry. To achieve a significant salt reduction, multiple application of extractive poultices may be required and will bring negative consequences related to the use of a lot of water, favoring the growth of microorganisms. Depending on the desired transport mechanism, the pore size distribution in the poultice must be correctly designed as a function of the pore size distribution of the plaster. For desalination based on the fast advection transport mechanism (drying poultice), the mean pore size of the poultice must be smaller than that of the substrate, and the poultice should dry quickly (Sawdy et al. 2008). On the other hand, for diffusion desalination (wet poultice), the salt concentration gradient determines the process, and therefore, it will work regardless of the pore size distribution. However, this method is very slow and typically it is applied only to small objects that can tolerate prolonged exposure to water. The mix design of the poultices therefore requires a careful choice of the components and their proportions (clayey, cellulosic and inert component).

In the study by Randazzo et al. (2020), the desalination tests were carried out on mock-ups of stratified plaster systems, soaked with $\mathrm{Na}_{2} \mathrm{SO}_{4}$ solution. In detail, poultices with different proportions of clay/cellulose pulp/sand were compared with the commercial product based on cellulose pulp and diatomaceous earth, which showed the best performance in terms of soluble salts extraction. The substantial difference seems to be the porosity distribution, characterized also by macropores mainly of large dimensions $(20-30 \mu \mathrm{m})$, which guarantee extraordinary efficiency in the first phase, during the wetting/dissolution process. On the contrary, previous results have shown that the most efficient extraction occurs with poultices with pores smaller than that of the substrate. However, whether it will be the chosen poultice, the main problem lies in the uncontrolled distribution of residual salt and the potential reiteration of salt-related problems (Sawdy et al. 2010).

Sacrificial plasters applied on the surface work on similar principle, but over a long-time range with a passive desalination effect. Their success is likewise variable (because changing of the salt system can worsen the situation), but, in addition to that, the new plaster will cover the original surface that can remain whitened once it will be removed (Dai and Zhong, 2019).

Requirements and criteria The most important requirement of this intervention is that the desalination effect is maximized, while keeping the induced change to the original surface and substrate to the minimum. Maximizing effectiveness means removing as much salt as possible, even in the depth of the masonry. It is very important to evaluate the long-term effectiveness, verifying if the deterioration processes will be interrupted or, at least, slowed down. Therefore, extraction measures should be followed with periodic monitoring and controls. In fact, there is a high risk that the treatment can induce further deterioration or aggravate the existing situation. Another important requirement in the case of Cultural Heritage is also to follow the principle of minimum intervention, to which some of treatments mentioned, although in some cases very effective, are in contrast, such as waterproofing by cutting the masonry and the application of sacrificial plasters (Franzoni, 2014).

Evaluation of treatments The evaluation of salt reduction treatments should verify the efficacy in eliminating salts. However, it would be important to determine the equilibrium $\mathrm{RH}$ of the new salt ion system remaining in the masonry. The $\mathrm{MC}$ and HMC (moisture content and hygroscopic moisture content) determination before and after treatment are very effective in the field of historical masonry investigations, as they can provide a reliable semi-quantitative distribution 
of hygroscopic salts (Nasraoui et al. 2009). However, this system is very invasive and requires multiple samplings. A non-invasive method based on a microwave system to detect moisture has been proposed by Olmi et al. (2006).

It is important to state that most of the studies to evaluate the effectiveness of extraction treatments are carried out either on stone monuments or on non-plastered brick walls (Vergès-Belmin and Siedel, 2005; Bourgès and VergèsBelmin 2008; Egartner et al. 2020). In this field, concerning mortars and plasters (especially if painted) invasive methods of evaluation cannot be used and more research efforts are needed to identify non-invasive salt evaluation methods (Ruiz-Agudo et al. 2011).

\section{Actions against biodeterioration}

Definition of the intervention The intervention aims at eliminating and slowing down biological growth. Different approaches have been adopted to isolate, identify, and quantify the types of microorganisms, and several methodologies and products have been used for their suppression. Indeed, to define the strategy against biodeterioration of mortars and plasters and to reduce the chances of recolonization, it is necessary to understand the causes leading to the uncontrolled growth of organisms. Normally, outdoor monuments, exposed to water, are colonized. In order to control biological colonization, indirect and direct methods can be applied (Pinna, 2017; Guillitte, 1995; Caneva et al. 2009). Indirect methods are related to control of environmental factors, such as acidity, humidity, temperature, and light, which directly affect the materials and contribute to the microorganism's growth. Direct methods involve an intervention, typically with a biocide on the biodegraded surface.

Critical issues Indirect methods can be adopted in indoor interventions, while they are hardly applicable outdoors. In most cases, the use of direct methods is the only solution. It is essential to be aware of the advantages and disadvantages of the different methods (Lo Schiavo et al. 2020), and to fit the best one for the case study, taking also into account the risks of recolonization.

Materials and methods: case studies Direct methods can be classified as physical and chemical systems. Physical methods involve the use of light irradiation and/or thermal treatments, while chemical methods include the use of conventional biocides as well as of innovative chemicals.

The use of monochromatic visible light (Bruno et al. 2017) is a physical method aimed to prevent or reduce the growth of photosynthetic microflora by blocking the photosynthesis. Unfortunately, it is ineffective against other non-photosynthetic microorganisms, while UV-C light $(\lambda$
$254 \mathrm{~nm}$ ) is able to inactivate most colonizing microorganisms (Baquedano Estévez et al, 2019; Pfendler et al, 2017). Thermal treatments, such as heat irradiation, microwave, and heat shock treatment are effective against lichens and green algae (Riminesi et al. 2016; Bertuzzi et al, 2013), but bacteria and some black fungi are insensitive to such methods (Pinna, 2017).

Chemical methods are mainly related to the use of biocides, which are generally a chemical able to inactivate biodeteriogen organisms that colonize a surface, while the term antifouling is referred to a surface deposited material or a coating, which is able to remove or prevent the growth of microorganisms on the surface where they are applied (Yebra et al 2004). There are two strategies against biodeteriogens: the first one is the inactivation of the already existing biomass, while the second is preventing recolonization, which is the objective of maintenance. The inactivation of biomass is usually achieved with biocides. Conventional biocides are based on chemicals used in agriculture. They are the most used because they are effective against a broad spectrum of organisms, and have been widely tested on mortars and plasters. After the suppression of microorganism and the removal of the biomass, a prevention plan against recolonization should be carried out (Delgado Rodrigues et al. 2011). This goal can be achieved by using antifouling coatings (Urzì et al. 2007), which can be made following two strategies: the first one involves the use of antimicrobial agents, while the second is based on the inhibition settlement of organism on the surface (La Russa et al, 2014).

Recently, natural-derived products have been tested as biocides (Bruno et al, 2019), such as capsaicin, extracellular enzymes, and essential oils (Veneranda et al, 2018; Silva et al, 2017; Palla et al, 2020). However, their use is still in the testing phase and lacks standardized protocols and knowledge of long-term effects on the treated substrate (Fidanza et al. 2019).

Nanotechnologies have been applied to address many issues related to treatment of built heritage (Baglioni et al. 2015), including those related to biodeterioration. Nanoparticles such as $\mathrm{SiO}_{2}, \mathrm{ZnO}, \mathrm{TiO}_{2}, \mathrm{Mg}(\mathrm{OH})_{2}, \mathrm{Ca}(\mathrm{OH})_{2}, \mathrm{ZrO}_{2}$, $\mathrm{TiO}_{2}$, and $\mathrm{Ag}$ have been widely tested for the treatment of mortars and plasters affected by biodeteriroation (SierraFernández et al. 2017; Ruffolo et al. 2019). Nanoparticles are able to produce surface nano-roughness, leading to a super-hydrophobic surface, which makes more difficult the adhesion and absorption of water, pollutants, and microorganism (self-cleaning effect) (Manoudis et al. 2009). Some nanoparticles, such as $\mathrm{TiO}_{2}$, have photocatalytic effects; thanks to this, they can keep the surface clean by promoting the oxidation of organic materials, including biological matter. However, nanomaterials have raised serious concerns in terms of human health and environmental risks; moreover, 
the long-term efficiency of such material is still unclear (Reyes-Estebanez et al. 2018).

Ionic liquids are organic salts, which are liquid at room temperature; they represent an alternative organic media for chemical processes (Welton, 2008). They also have antimicrobial activity (Pendleton et al. 2015), for this reason, recently they have been tested as biocide for the treatment of architectonic surfaces (Archismita et al. 2018). Table 1 summarizes the advantages and disadvantages of the methods discussed.

Requirements and criteria The main aim of the cleaning of a bioderiorated surface is the "killing" and removal of the microorganisms responsible for the biodeterioration.

Treatments should have a low toxicity for the operators and for the environment. The treatments must not leave harmful residues on the surface. The effectiveness of the treatment should be as long as possible in order to assure also less maintenance. Lastly, a suitable treatment must not hinder the possibility to carry out other operations, such as consolidation and cleaning, this feature is identified as re-treatability.

Evaluation of treatments If applicable, indirect methods against biodeterioration generally assure minimum risks for the materials to be restored. Unfortunately, most of the time plasters and mortars are located outdoors, or indoor but in large uncontrolled environments.

How to choose the proper direct method to be applied, most of the time the use of a wide spectrum biocide assures good results and generally helps the preliminary disinfection and cleaning of the surfaces. The use of other methods is in evolution, testing is on-going, but currently not very diffused. The lack of resources for monitoring over time is problematic as microbiological growth requires some time to represent. More research must be devoted to assess longterm performance of direct and indirect interventions. For microorganism determination, significant costs are associated because in order to check the performance of the treatments; besides visual inspections, different analyses with different complexity are necessary.

The addition of new materials When a new material is used, it is very important to document with a high level of detail what has been done, how much material was used and in which areas. This information will be of fundamental importance for those who will have to treat the same surface in the future. By implementing regular monitoring, the necessary knowledge on the long-term duration of treatments will be acquired. The ideal treatment does not exist in practice, and so tolerance limits derived from laboratory measurements and repeated observations over time can be introduced.

Performance requirements over the long term are referred to the solid state of the material after setting, when it has become part of the porous system. The working properties are the characteristics of the product during the intervention, to make it easy and feasible, and refer to the material in the liquid state before it takes effect (Cather, 2006).

The characterization of the original mortar, its historical context and their fundamental properties must be obtained in order to select or design the correct new material (Henriques et al. 2005).

Table 1 Summary of pros and cons of the main methods against biodeterioration

\begin{tabular}{|c|c|c|c|c|}
\hline \multirow[b]{2}{*}{ Method } & \multicolumn{2}{|l|}{ Purpose } & \multirow[b]{2}{*}{ Advantages } & \multirow[b]{2}{*}{ Disadvantages } \\
\hline & Removal & Preventing & & \\
\hline Monochromatic visible light & $\mathrm{X}$ & $X$ & $\begin{array}{l}\text { Easiness } \\
\text { Safe }\end{array}$ & $\begin{array}{l}\text { Effective only against phototrophs } \\
\text { Possible production of residues used by } \\
\text { other microorganisms }\end{array}$ \\
\hline UV-C & $\mathrm{X}$ & $\mathrm{X}$ & $\begin{array}{l}\text { Easiness } \\
\text { Irreversible cellular and molecular } \\
\text { damages }\end{array}$ & $\begin{array}{l}\text { Cannot be used in the presence of } \\
\text { people } \\
\text { Possible damages to painted surfaces }\end{array}$ \\
\hline $\begin{array}{l}\text { Microwave, heat treatment, shock heat } \\
\text { treatment }\end{array}$ & $X$ & & $\begin{array}{l}\text { Portability } \\
\text { Safe for the cultural asset and for the } \\
\text { humans }\end{array}$ & $\begin{array}{l}\text { Possible production of residues used by } \\
\text { other microorganisms } \\
\text { Possible water diffusion } \\
\text { To be used with other treatments }\end{array}$ \\
\hline Natural-derived products & $X$ & $\mathrm{X}$ & $\begin{array}{l}\text { Effectiveness } \\
\text { Suitable for indoor environments }\end{array}$ & $\begin{array}{l}\text { Not suitable for outdoor } \\
\text { Lacking of standardized protocol }\end{array}$ \\
\hline Conventional biocides & $\mathrm{X}$ & & $\begin{array}{l}\text { Effective against a broad spectrum of } \\
\text { organisms }\end{array}$ & Medium-term efficacy \\
\hline $\begin{array}{l}\text { Innovative biocides nanomaterials- } \\
\text { ionic liquids }\end{array}$ & $X$ & $\mathrm{X}$ & Tunable properties & $\begin{array}{l}\text { Lacking of standardized protocol } \\
\text { Concerns of human health and environ- } \\
\text { mental risks. Missing of long-term } \\
\text { behavior }\end{array}$ \\
\hline
\end{tabular}




\section{Consolidation treatments}

Definition of the intervention Consolidation is a corrective action to remedy the loss of cohesion of a building material. The problems of disintegration, powdering or lack of cohesion manifest themself as the presence of loose material in the form of dust or very minute fragments due to a loss of adhesion between single particles or small groups of particles (see the voice "crumbling" in Ewa Glossary 2015). The intervention called consolidation must be distinguished from those aimed at re-adhering a layer of plaster (flake of material) or a much bigger portion of plaster which are treated in the next section. The intervention of consolidation aims at linking and binding together small detached elements by filling the gaps between them. For this intervention, a consolidating liquid (a solution or a dispersion, organic or inorganic) is introduced into the porous material that should penetrate preferentially into the powdering part of the mortar. After the material has absorbed the liquid product, chemical and physical processes will take place, leading to the formation of a solid (new binder) through a setting mechanism. The final distribution of the consolidant and the efficiency of the intervention depend on several factors: the nature of the consolidant itself, the method of application, the surrounding environmental conditions, and the properties of the powdering plaster/mortar.

Critical issues Consolidating treatments are irreversible, even if conducted with consolidants that maintain their solubility (i.e., organic synthetic polymers), because once applied to a porous system, capillary forces will never allow the consolidant in solution to be removed. It is therefore essential to select a material compatible with the original (for a definition of compatibility, see Apostolopoulou et al. 2017) and stable to ensure a durable intervention. For mortar and plaster, the best compatible materials are inorganic, and set through a reaction forming insoluble products. The distribution of the consolidant should match the degraded substrate and produce a homogeneously distributed porosity (ideally similar to that of the original system). Consolidation treatments can hardly achieve more than few centimeters in depth, but it is important to avoid a total closure of the pores in the surface as it would modify the movements for water, potentially amplifying the harmful effects caused by the presence of water and soluble salts (Matteini 2008). It has to be pointed out that the consolidation treatment, if conducted with organic polymers, can lead to a water repellent feature, since many organic polymers used for treatment have a hydrophobic nature.

It has to be taken into account that if the cause of deterioration is present and active, no consolidation treatment will be successful over time. Soluble salts represent a critical issue especially if we are dealing with consolidation. The presence of soluble salts can cause the failure of a consolidation procedure in two ways: first through the interaction with the consolidant and/or the setting mechanism. This is a typical issue for inorganic consolidants. The second one is related to the well-known devastating effect of salt crystallization: once the consolidation has taken place, soluble salts trapped in the material have less space to expand when they crystallize and generate greater pressures into the pores (Snethlage and Wendler, 2000). The consolidation of a salt contaminated mortar or plaster remains a problem without any perfect solution, where the best option remains to develop a system compatible with the salts movement ("learn to live with it"). Further research on this aspect is desirable.

Materials and methods: case studies In cases where preconsolidation is necessary, the chosen product must be able to protect the unsafe parts, remaining on the surface only for the necessary time, and then be easily removed without hindering future treatments. Cyclododecane was the most widely used temporary consolidant due to its capacity to sublimate (Rowe and Rozeik, 2009). Unfortunately, not only is there evidence of its toxicity (Vernez et al. 2010) but also is no longer produced. An alternative has been proposed with menthol (Xiangna et al. 2016).

The classes of materials used for consolidation of mortars and plaster are hydroxides of alkaline earth metals (Ca, Ba) silicon compounds, and organic polymers (Torraca 2009).

In the past, consolidating products included mainly lime and gypsum, but also organic materials, such as vegetable oils, waxes, and natural resins (Satish, 2013). With the development of synthetic chemistry, barium water, silicabased consolidation methods (such as ethyl silicate), synthetic polymers have found applications (Siegesmund and Snethlage, 2011). Unfortunately, some of these substances did not meet the compatibility and performance requirements for the consolidation treatment.

In general, considering the nature of mortars and plaster, the use of inorganic materials as consolidants is preferred, since they are generally more stable, less susceptible to microbiological attacks than organic compounds (Matteini et al. 2011). During the last century, limewater was used for the consolidation of wall paintings (Denninger, 1958), and has also been tested as a consolidator for mortar (Slížková et al, 2015). The main drawback is the low solubility of calcium hydroxide and the consequent need to apply large amounts of water. Calcium hydroxide nanoparticles have been developed since the early 2000s to obtain a better efficiency of lime-based consolidants (Dei and Salvadori, 2006). Silica-based consolidants are particularly compatible for the consolidation of earth mortars. Recently, ammonium phosphates were proposed for the consolidation of calcareous 
substrates and mortars (Masi and Sassoni, 2020; Sassoni and Franzoni, 2020; Franzoni et al. 2015; Matteini et al. 2011).

A thin film of calcium oxalate can protect outdoor exposed structures composed of carbonate stone that are exposed to acidic environments, thanks to the very low solubility of this salt with respect to the calcium carbonate (Liu et al, 2006; Matteini et al. 1994). A standard treatment involves the use of ammonium oxalate. Calcium phosphate has been confirmed to be more effective than oxalate as a consolidant; thus, an effective consolidation and protection treatment of calcareous artefacts could be ammonium phosphate application followed by ammonium oxalate (Osticioli et al. 2017).

The most important physical-chemical characteristics and pros/cons of common consolidation products are given in Table 2. Those pros/cons have to be intended as general, in some specific situations a disadvantage can turn into an advantage and vice versa.
The method of applying the consolidant depends on its nature, on the capacity of the mortar to absorb it, and on the shape, position, and exposure of the element to be treated. The method of application also determines the depth of penetration. With the spray mode, a surface film is formed, not homogeneous; care must be taken in case of non-cohesive material. The brush itself is a capillary system. Beware of the fact that the concentration and viscosity of the product will increase as it remains on the brush. The syringe allows you to apply large quantities of product that can be directed only where it is needed (Fig. 6). The concentration is stable and can also be used in the case of a loose substrate. The poulticing method with cellulose pulp guarantees deep penetration (Michalski, 2008).

Requirements and criteria Since reversibility is a concept that cannot be applied to the consolidation of a porous system, focus is given to allow "re-treatability" and

Table 2 Summary of Pros and Cons of the main consolidants

\begin{tabular}{|c|c|c|}
\hline Product & Pros & Cons \\
\hline $\begin{array}{l}\text { Lime water } \\
\mathrm{Ca}(\mathrm{OH})_{2} \\
\text { Aqueous solution } \\
\text { Max concentration } 0.16 \mathrm{wt} \%\end{array}$ & $\begin{array}{l}\text { Chemical compatibility of formed } \mathrm{CaCO}_{3} \text { with } \\
\text { lime mortar }\end{array}$ & $\begin{array}{l}\text { Very diluted solutions, it requires many appli- } \\
\text { cations, i.e., high amounts of water } \\
\text { High pH } \\
\text { Requires time for setting }\end{array}$ \\
\hline $\begin{array}{l}\text { Barium water } \\
\mathrm{Ba}(\mathrm{OH})_{2} \\
\text { Aqueous solution } \\
\text { Max concentration } 5.6 \mathrm{wt} \%\end{array}$ & $\begin{array}{l}\text { Sufficient concentrated solutions } \\
\text { High stability of formed } \mathrm{BaCO}_{3}\end{array}$ & $\begin{array}{l}\mathrm{BaCO}_{3} \text { slightly differs from } \mathrm{CaCO}_{3} \text { in terms of } \\
\text { physical properties } \\
\text { High pH } \\
\text { Requires time for setting }\end{array}$ \\
\hline $\begin{array}{l}\text { Nanolime } \\
\mathrm{Ca}(\mathrm{OH})_{2} \\
\text { Dispersion of particles (size } 50-300 \mathrm{~nm} \text { ) in } \\
\text { alcohol } \\
\text { Max concentration } 8 \mathrm{wt} \%\end{array}$ & $\begin{array}{l}\text { Sufficient concentrated dispersions } \\
\text { Chemical compatibility of formed } \mathrm{CaCO}_{3} \text { with } \\
\text { lime mortar }\end{array}$ & $\begin{array}{l}\text { Poor penetration } \\
\text { Formation of white hazes due to particle size } \\
\text { and fast evaporation of dispersing liquid }\end{array}$ \\
\hline $\begin{array}{l}\text { Nanosilica } \\
\mathrm{SiO}_{2} \\
\text { Dispersion of particles (size } 7-125 \mathrm{~nm} \text { ) in } \\
\text { water } \\
\text { Max concentration } 50 \mathrm{wt} \%\end{array}$ & $\begin{array}{l}\text { Good consolidation effect } \\
\text { Chemical compatibility of } \mathrm{SiO}_{2} \\
\text { with silica-based plaster components }\end{array}$ & $\begin{array}{l}\mathrm{SiO}_{2} \text { differs from } \mathrm{CaCO}_{3} \\
\text { Poor penetration and formation of surface } \\
\text { deposits }\end{array}$ \\
\hline $\begin{array}{l}\text { Ethyl silicate, TEOS } \\
\text { Monomer or oligomer } \\
\text { Pure or diluted in organic solvent } \\
\text { Max concentration about } 99 \text { wt } \%\end{array}$ & $\begin{array}{l}\text { Good consolidation effect } \\
\text { Good penetration } \\
\text { Chemical compatibility of } \mathrm{SiO}_{2} \\
\text { with silica-based plaster components }\end{array}$ & $\begin{array}{l}\mathrm{SiO}_{2} \text { differs from } \mathrm{CaCO}_{3} \\
\text { Initial hydrophobicity and long setting time }\end{array}$ \\
\hline $\begin{array}{l}\text { Acrylic polymers } \\
\text { Solution in organic solvent, or water disper- } \\
\text { sion } \\
\text { Usually used at } 1-5 \mathrm{wt} \%\end{array}$ & $\begin{array}{l}\text { Good consolidation effect } \\
\text { Fast setting time }\end{array}$ & $\begin{array}{l}\text { Organic nature, i.e. incompatible with most } \\
\text { plaster/mortars materials } \\
\text { Prone to deterioration }\end{array}$ \\
\hline $\begin{array}{l}\text { Ammonium phosphates } \\
\left(\mathrm{NH}_{4}\right)_{2} \mathrm{HPO}_{4} \\
\text { Aqueous Solution } \\
\text { Usually used at } 5 \mathrm{wt} \%\end{array}$ & $\begin{array}{l}\text { Sufficient concentrated solutions } \\
\text { Absence of toxicity } \\
\text { Very low solubility of the reaction products } \\
\text { (calcium phosphate). Good penetration into } \\
\text { the stone } \\
\text { Good consolidation effect }\end{array}$ & Calcium phosphate phases differs from $\mathrm{CaCO}_{3}$ \\
\hline $\begin{array}{l}\text { Ammonium oxalate } \\
\left(\mathrm{NH}_{4}\right)_{2} \mathrm{C}_{2} \mathrm{O}_{4} \\
\text { Aqueous Solution } \\
\text { Usually used at } 5-7 \mathrm{wt} \%\end{array}$ & $\begin{array}{l}\text { Sufficient concentrated solutions } \\
\text { Absence of toxicity } \\
\text { Very low solubility of the reaction products } \\
\text { (calcium oxalate) }\end{array}$ & Poor penetration \\
\hline
\end{tabular}




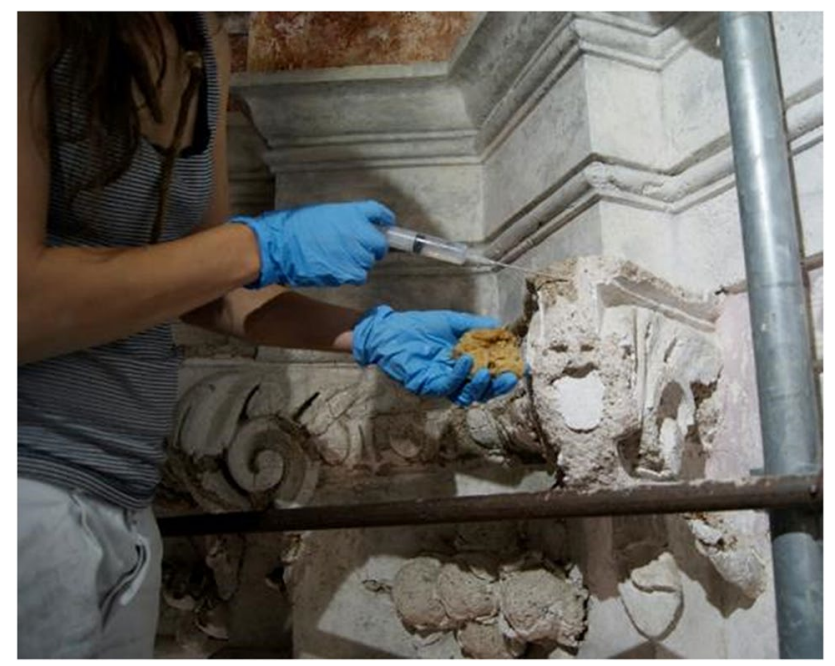

Fig. 6 Consolidation of a disaggragated mortar using Ethyl silicate applied by syringe

compatibility. The concepts of re-treatability and compatibility provide the framework for a strictly scientific approach to conservation and restoration problems.

Important properties are the ability to confer to disintegrated material good/better cohesion, also repairing microcracks. Consolidation treatments with good chemical, mineralogical, and physical-mechanical compatibility with plasters and mortars are obtained by using products having low shrinkage, as well as having several characteristics such as expansion coefficient, hydric behavior, modulus of elasticity, and mechanical resistance that have to be similar to the material to be treated. Furthermore, the ones with good chemical and physical stability should be preferred. The treatment must not activate deterioration phenomena and must not form surface film/crust. Finally, it must be resistant to biodeterioration.

The working properties are the ease of preparation, the good penetration capacity in the support (medium-low molecular weights, low viscosity, good wettability, and spontaneous diffusion). The penetration ability of the consolidant depends on the liquid viscosity, surface tension, and also on the particle size if we are dealing with a dispersion (Snethlage and Sterflinger, 2011). Other properties to be considered are a reasonable setting time, minimum water content and initial water release, low toxicity, and compatibility with other treatments.

Evaluation of treatments The assessment of a consolidation treatment can be carried out by comparing selected properties measured on treated and not-treated mortar. Such parameters include surface cohesion, water absorption, porosity and pores size distribution, chromatic variation and appearance, and microscopic and chemical features (to check the distribution of the consolidant into the material and the microstructural variation induced by the treatments).

Only a limited number of these parameters can be assessed in situ. Standardized measuring methods for testing mortars properties exist and some have been modified for testing historical mortar (Borsoi et al. 2012; Drdácký and Slížková 2013). When methods are missing, adoption of tests for stone (Laurenzi Tabasso and Simon 2006) can be utilized. In situ tests include the Karsten tube or sponge tests to evaluate the water absorption, the DRMS (drilling resistance measurement system), ultrasonic velocity and peeling test to indirectly evaluate cohesion. Colorimetric measurements evaluate chromatic variations. Laboratory tests are more sensitive methods; however, the conditions are standard and do not correspond to the real situation. Laboratory tests are porosity measurement evaluated by microscopic observations or mercury intrusion porosimetry (MIP), water absorption test (EN 1015-18:2002), and durability tests such as freeze-thaw cycles, salt crystallization cycles, and wetdry cycles (Arizzi et al. 2012).

\section{Injection grout}

Definition of the intervention The aim of re-adhesion of delaminated plaster can be addressed in various manners. When stabilization is done by injection of a fluid mortar the intervention is called "grouting." An injection mortar has bulking properties, and it can be inserted behind and/ or between plaster layers to fill voids and restore adhesion between the layers, once it has set (Griffin, 2004; BiçerȘimşir and Rainer, 2013). Indeed, plastered surfaces are highly complex porous multilayer systems applied on an immovable substrate that can often show delamination phenomena, both between these layers and between them and the wall support. Since this intervention aims to stabilize the problems of lack of adhesion (detachment/delamination) between coherent layers that are about to fall, it is among the most urgent problems to be treated. Injection mortars are composed of one or more binders, aggregates, fillers, additives, and a dispersing fluid, which is typically water. Specially formulated pre-mixed hydraulic mortars are normally used (with low specific weight for vaults and floors).

Critical issues Injection grouting is an irreversible operation and grouted areas can be difficult to re-treat (Rickerby et al, 2010); therefore, physical-chemical compatibility with the original materials is essential and the grout must be adapted to specific deterioration phenomena. Moreover, this intervention is imprecise and very risky as it involves plasters in fragile conditions. Major challenges include difficulty in accurate assessment of the severity, the location and of the 
extent of the problem, lack of accuracy, and control during the intervention/injection.

Another issue is related to the use of water, which is by far the most widely used suspension medium for grouting. Water is necessary for the chemical setting of a hydraulic binder, and to improve the fluidity of the injection grout. However, the use of water must be kept to a minimum to limit segregation, shrinkage, and the formation of microcracks. Water is also dangerous for some sensitive materials (e.g., gypsum or clay or other components of stucco artworks) or in case of contamination by soluble salts, they can be reactivated (Caroselli et al. 2020). To reduce the need for water in the grouting mix, superplasticizers are usually added. These polymers increase injectability, slow hydration, and reduce water requirements (Flatt and Girardet, 2000). However, their use can form new soluble salts (Pasian et al. 2017).

Materials and methods: case studies The materials used, the techniques for implementing the grouting, their properties and performance, and the methods for evaluating them were deeply examined (Biçer-Șimşir et al. 2009; Biçer-Şimşir and Rainer, 2013). Proper preparation of the substrate is essential before injecting the grout. The delaminating layers should be well cohesive and clean. The debris, which has accumulated in the voids behind the wall, must be thoroughly cleaned. For this purpose, they can be sucked out and water or water and alcohol can be used to wash the cavity. The pre-wetting with water also serves to reduce the absorption of water from the grout mix. This is important so that grout water content is maintained constant and setting can occur properly. The holes through which the grouting could escape must be sealed to prevent the dripping onto the surface (BiçerŞimșir and Rainer, 2013). The grout is injected into the void attempting to fill it from below upwards. It is important to be ready with supports to be left in place while the grout sets (particularly in the case of horizontal architectural surfaces, Fig. 7). Depending on the type of plaster, applying pressure to the grouted area can help realign a warped plaster and provides better contact during the setting of the grout resulting in a better adhesion.

In specific cases, an alternative can be the use of pivots; examples of this type can be found in the Saint John convent in Müstair (Switzerland) and in the Cathedral of Cremona (Italy). In the vast majority of cases, conservators favor commercial pre-mixed mortars, because they are easy to use, well tested, and provide a guaranteed intervention over time. However, in very particular cases, it is necessary to design specific mortar mixes. The procedure of "mix design" is treated in the next section. Few publications describe a methodology for the design and testing of grouts formulated ad hoc on-site (Piqué et al. 2010). Mix design should

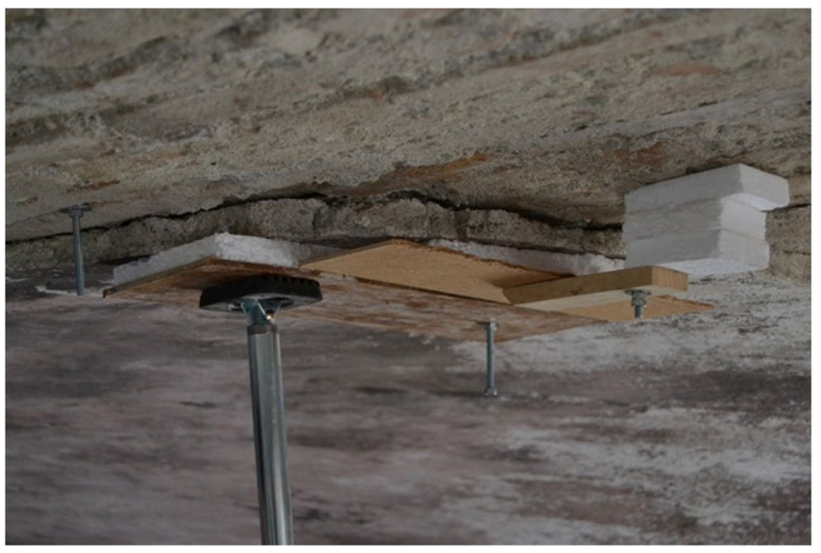

Fig. 7 Supports of a detached plaster in a vault. Supports must be ready before starting grouting, but have a fundamental role after the intervention while the grout sets

start with the criteria of the intervention and a simple test program needs to be developed based on the desired properties for the grout. For this purpose, the GCI manual on testing grout is of great help as it also provides simplified testing procedures to be conducted on site (Biçer-Şimşir and Rainer, 2013). Pasian et al. provide an excellent recent case study illustrating the development of ad hoc formulations following an iterative process on a lime-based wall painting in India (Pasian et al. 2020).

To address the problem of water, recent research focused on finding an alternative liquid to partially replace water. Grouts with reduced water content were designed with ethanol. The addition of egg white in small amounts was also tested following extensive theoretical and practical research carried out at the Courtauld Institute of Art (Tringham and Rickerby, 2020). Mineralogical and microstructural analysis showed that the presence of both water reducing components, ethanol and albumin, provided a higher degree of carbonation and of pozzolanic reaction. On the other hand, ovalbumin reduced the magnitude and speed of both carbonation and hydraulic reactions, while ethanol reduced the magnitude and speed of carbonation, but did not appear to interfere substantially with hydraulic reactions. Previous results also showed that water reducing mortars were characterized by high porosity and water vapor permeability, as well as good cohesion (Pasian et al. 2018).

In case of narrow delamination ( $\leq 2 \mathrm{~mm}$ wide), the grout injected must be able to flow within fine spaces reestablishing adhesion. Recently, experimental grouts composed of ammonium oxalate with $\mathrm{CaCO}_{3}$ aggregate were developed and tested showing that a cohesive micro-grout can be achieved through the reaction formation of calcium oxalate. Though limited, the calcium oxalate products formed during the reaction of ammonium oxalate and calcium carbonate were sufficient to bind the 
aggregates into a cohesive matrix and provide adhesion to the delaminating layers (Porter et al. 2020).

Commercial products have also evolved and specialized and nowadays it is possible to find very particular formulations on the market, such as grouting for gypsum plasters or adhesive mortars to reattach mosaic tesserae or stucco fragments.

Requirements and criteria Biçer-Șimșir and coworkers have reviewed the publications regarding working properties and the long-term performance characteristics of injection grout (Biçer-Șimșir and Rainer, 2013). The most important working property for an injection mortar is undoubtedly the fluidity and therefore the ability to penetrate deeply into the gaps. This feature is directly related to the amount of water added to the mix which also affects shrinkage, porosity, and mechanical resistance in the hardened state. Regarding the performance characteristics, a wide range of properties must be considered: the injection mortar should be compatible with the original substrate and the surface materials. Therefore, the mechanical resistance should be lower than the original plaster to avoid excessive mechanical stress, while the capillary absorption of water and vapor permeability must be similar to that of the original. Since the new mortar should recreate the continuity between detached layers, it should ensure adequate structural stability and good adhesion to the substrate. Finally, the concentration of soluble salts in the mortar should be as low as possible.

Evaluation and choice of treatments Reliable analyses and testing procedures have been researched and laboratory and in situ tests have been proposed (Biçer-Şimşir 2013, Pasian et al. 2019). However, reference standards for testing of non-structural lime-based injection grouts are not currently available.

Recently, investigation techniques have been tested to provide an objective alternative to support the simple but subjective "knock test" practiced by conservator-restorers as a routine in situ. These are for example 3D optical scanning, able to document spatial deformations. Another technique is video holography/laser speckle, where the acoustic vibrations of the surface are visualized and recorded. Among these, infrared thermography has been used to assess delamination, positioning of the grout, and the setting process over time (Agnew and Wong 2014).

\section{Substitution of materials: fills and repair}

\section{Definition of the intervention}

The use of repair mortars is necessary when at least one of these situations occur: (i) there are portion of plaster lost; (ii) historic mortars and plasters are too deteriorated to be effectively and efficiently preserved; or (iii) the original material is not attributed of a sufficient value to be transmitted to future generations and the decision of its substitution is taken. In these cases, a mortar mix is designed to replace the missing one. The new material must be modeled and then applied by adapting to the required shape and surface finishing. The successful design of a mortar for repairing an architectural element starts from a clear understanding of its function. The resulting desirable properties/ technical requirements are achieved by varying the nature of the mortar component and their proportions (Hughes, 2012).

\section{Critical issues}

The objective is not to design a mortar that can last for a long time, but to prepare a material compatible and able to protect the original one (as another mortar, or the plaster or the ancient masonry surrounding the loss). Particularly important is the compatibility between the existing substrate and the repair mortar once in the hardened state, in order to avoid that the new mortar remains intact while the surrounding material is lost (Fig. 8). Difficulties are linked to the restriction in sampling and therefore determining the properties with physical-mechanical tests of the ancient mortars (Valek and Veiga, 2005). Repair mortars must resist the aggressive environments that have caused the deterioration of the original one. However, traditional materials used as binders, namely aerial lime, form relatively weak mortars with a slow hardening rate, and meeting current construction constraints proves to be difficult (Van Balen et al. 2005). In other words, it is important to reach the delicate balance

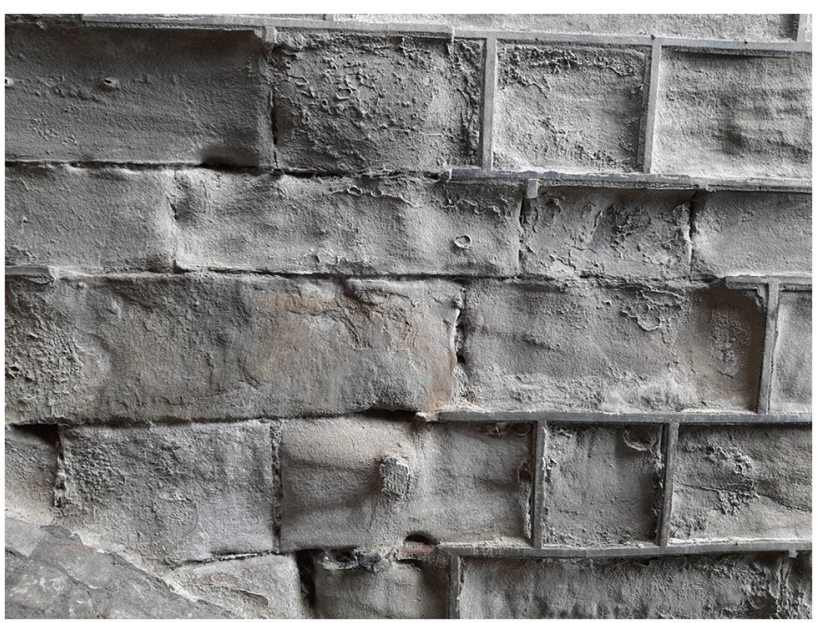

Fig. 8 Example of a reintegration of a repointing mortar. In this case, the new mortar has remained intact while the surrounding softer stone has eroded due to atmospheric agents 
between a durable and a compatible intervention as well as the proper protection of the existing material.

\section{Materials and methods: case studies}

"Mix design" is intended as the choice of the components of a mortar (binder, aggregate, additives and water) and their proportions to meet the desired requirements (Teutonico et al. 1993). The variation of the composition allows to obtain different physical and mechanical properties of the mortar, in relation to a specific function. The type of binder and its proportion in the mix is very important in determining the fresh and hardened properties of a mortar. Different types of binders determine different physical properties of mortars, for example, by increasing the hydraulicity, the strength properties of lime-based mortars increase, and the average pore size and total porosity decrease (Veiga, 2017). The aggregate usually occupies about two-thirds of the volume of the mortar, and therefore has an important effect on its performance, e.g., by varying the size and distribution of the aggregate, the shape, the mineralogical content, and the quantity, variations in the workability and properties of the hardened mortar are produced. The aggregate reduces shrinkage, has a high elastic modulus, contributes to the mechanical characteristics, promotes carbonation, and influences porosity. Various additives can also be introduced to alter or impart specific properties, for example, the addition of a blowing agent to improve frost resistance, but they also include setting accelerators or retarders, plasticizers, pigments, and fibrous substances. The use of additives should not be done without a full understanding of the intentional and unintended effects on physical and mechanical properties (Hughes, 2012).

To improve performance, it is important that the new mortar adheres well to the substrate; therefore, crumbly material must be eliminated or consolidated. Finally, the mixing procedure (force, speed, and time) and the application have a major effect on the performance of the intervention.

\section{Requirements and criteria}

The fundamental requirement of a repair mortar is its compatibility and reversibility, while secondly, long-term durability, sustainability, and harmonization with the existing mortar are important, if the mortar is exposed. Reversibility in this case requires that the new mortar can perform the function for which it was designed, but it must be possible to remove it without damaging the surrounding original material, when required.

Functional requirements depend on the mortar functions. For example, water protection and mechanical resistance are important for a bedding mortar because the aim is to guarantee the stability of the masonry and to protect the building from the external environment; surface resistance and water protection are important for a plaster, while porosity and low strengths are important for temporary macro-porous mortars and sacrificial plasters. Once the functional requirements have been established, the corresponding technical requirements can be determined. For example, protection against water means the preparation of a mortar with low capillary water absorption, low water absorption coefficient, and asymptotic value. While designing the new mortar, the type of aggregate (quantity, particle size and characteristics) has to be chosen and calibrated to obtain these low values (Henriques, 2005).

\section{Evaluation of treatments}

After having chosen compatible binder and aggregate to the ancient mortar, the task is to determine the proportions between them in order to obtain certain properties. To do so, it would be necessary to prepare several specimens with mixtures at different percentages, and testing a set of important properties, establishing tolerance limits, and finally choosing the most suitable mixture for the specific case. There is currently no internationally validated test set for lime-based mortars for reintegration (Arizzi et al. 2012). The Rilem committee (Papaianni et al. 2019) stated that a revision or adaptation of the current standard test methods is advised, for a more realistic and effective evaluation of lime-based mortars. Furthermore, as it has been done for injection mortars (Biçer-Şimşir and Rainer, 2013), it is proposed to adapt and develop simple test methods that can be done in situ by the restorers, facilitating the quality control of the repair work.

Important properties to be measured are porosity and pore size distribution, capillary water absorption, drying, water vapor permeability, hygroscopicity, resistance toward free-thaw and salt crystallization cycles, mechanical strength (compressive and tensile), modulus of elasticity, deformability, early and long-term shrinkage, adhesion, and thermal expansion coefficient.

\section{Concluding remarks}

The conservation of mortars and plasters is a very complex issue which necessarily includes a wide range of problems that must be addressed. Despite being a specific class of materials, they are inextricably linked to the built heritage, and therefore, they must be considered within the general scheme of protection of historic buildings. It is not possible to design an intervention without starting from a thorough knowledge of the whole building system, trying above all to identify the causes and processes that have produced the deterioration and that are probably still active. In this sense, 
the diagnostic phase and the contribution of materials science is fundamental.

Most of the deterioration causes affecting mortars and plasters are linked to the presence of water (liquid or vapor), a source of soluble salts, and major microclimatic fluctuations. Therefore, it is very important to first address these causes, trying to solve them or, if it is not possible, at least to mitigate them and manage them through maintenance procedures. Preventive conservation has exactly this purpose and guarantees the maximum effectiveness of our action.

Once the causes have been removed or at least addressed, deteriorated mortars and plasters can be treated according to the specific problem. Scientific research should direct the maximum effort to face the most demanding problems on the subject of intervention on mortars and plasters. Soluble salts have been identified as a major issue affecting these materials. The main problem lies in the evaluation of their presence, in particular during and after a reduction intervention. In cases of valuable plasters, this is not always possible, due to the invasiveness of the evaluation measures. Salt reduction attempts should be avoided without proper long-term evaluation of these treatments. Furthermore, the consolidation of a disintegrated mortar or plaster, caused by the action of soluble salts, remains a problem with no adequate solution. The best option at the moment is the development of a system that can be compatible with the movement of the present salts.

Biocolonization can be harmful for mortars and plasters. Indirect removal methods can be adopted in indoor interventions, while they are difficult to apply outdoors, in most cases the use of direct methods is the only solution. It is essential to be aware of the risks of recolonization.

The main challenges in the case of detachment and delamination include difficulties in precisely assessing the severity, location, and extent of the problem, together with the lack of accuracy and control during the injection of the mortar grout. Another critical point is the reduction of water during grouting, as has been addressed in recent studies. A simple formulation prepared on site or a pre-mixed product with this characteristic would be an interesting step forward in the sector.

In extreme cases, when the conservation of the ancient material is not compatible with the protection of the building, because the function of the mortar is hindered, it is necessary to reintegrate the missing parts or replace those that are too damaged. In this case, the compatibility criterion must guide the design of the new mortar, favoring conservation over existing original materials. There are currently no internationally validated tests set for lime-based mortars and a review or adaptation of the current standard test methods for historic mortars seems desirable.

The importance of monitoring and the scheduling of the maintenance actions are the best practice to guarantee long-term conservation of mortars and plasters, and they represent the most effective and the cheapest measures to afford the inexorable change of our built heritage.

Authors' contributions MC: organization and writing of the manuscript. S.R: writing of the manuscript (removal of biodeterioration, consolidation). FP: writing of the manuscript (methodological introduction), revision of the text.

Funding Open Access funding provided by SUPSI - University of Applied Sciences and Arts of Southern Switzerland.

\section{Declarations}

Conflicts of interest The authors declare that they have no conflicts of interest.

Open Access This article is licensed under a Creative Commons Attribution 4.0 International License, which permits use, sharing, adaptation, distribution and reproduction in any medium or format, as long as you give appropriate credit to the original author(s) and the source, provide a link to the Creative Commons licence, and indicate if changes were made. The images or other third party material in this article are included in the article's Creative Commons licence, unless indicated otherwise in a credit line to the material. If material is not included in the article's Creative Commons licence and your intended use is not permitted by statutory regulation or exceeds the permitted use, you will need to obtain permission directly from the copyright holder. To view a copy of this licence, visit http://creativecommons.org/licenses/by/4.0/.

\section{References}

AA.VV. (1999) GRADOC-Graphic Documentation Systems in Mural Painting Conservation: research seminar, Rome 16-20 November 1999

Aceto M (2021) The palette of organic colourants in wall paintings. Archaeol Anthropol Sci. https://doi.org/10.1007/ s12520-021-01392-3

Agnew N, Wong L (2014) The Conservation of Cave 85 at the Mogao Grottoes, Dunhuang: a collaborative project of the Getty Conservation Institute and the Dunhuang Academy. Getty Publications

Apostolopoulou M, Aggelakopoulou E, Siouta L, Bakolas A, Douvika M, Asteris PG, Moropoulou A (2017) A methodological approach for the selection of compatible and performable restoration mortars in seismic hazard areas. Construct Build Mat 155:1-14

Archismita M, Castillo IF, Müller DP, Gonz $\mu$ lez C, Eyssautier-Chuine S, Ziegler A, de la Fuente JM, Mitchell SG, Streb C (2018) Polyoxometalate-Ionic Liquids (POM-ILs) as anticorrosion and antibacterial coatings for natural stones. Angew Chem Int Edit $57: 14926-14931$

Arizzi A, Cultrone G (2021) Mortars and plasters: how to characterise hydraulic mortars. Archaeol Anthropol Sci. https://doi.org/10. 1007/s12520-021-01404-2

Arizzi A, Viles H, Cultrone G (2012) Experimental testing of the durability of lime-based mortars used for rendering historic buildings. Construction and Building Materials 28(1):807-818

Arnold A (1996) Altération et conservation d'oeuvres culturelles en matériaux poreux affectés par des sels. In Le dessalement des 
matériaux poreux: 7èmes journées d'études de la SFIIC, Poitiers, 9-10 mai 1996, pp. 3-20

Arnold A, Zehnder K (1991) Monitoring wall paintings affected by soluble salts. In: Cather $\mathrm{S}$ (ed) The conservation of wall paintings: Proceedings of a Symposium Organized by the Courtauld Institute of Art and the Getty Conservation Institute, London, July 13-16, 1987

Avrami E, Macdonald S, Mason R, Myers D (2019) Values in heritage management: emerging approaches and research directions. Getty Publications

Baglioni P, Carretti E, Chelazzi D (2015) Nanomaterials in art conservation. Nat Nanotechnol 10:287-290

Baquedano Estévez C, Moreno Merino L, de la Losa RA, Durán Valsero JJ (2019) The lampenflora in show caves and its treatment: an emerging ecological problem. Int J Speleol 48:249-277

Becker H (2021) Pigments - colorants terminology: to each its own name. Pigment nomenclature in the ancient Near East, Greece, and Rome. Archaeol Anthropol Sci. https://doi.org/10.1007/ s12520-021-01394-1

Bertuzzi S, Candotto Carniel F, Pipan G, Tretiach M (2013) Devitalization of poikilohydric lithobionts of open-air monuments by heat shock treatments: a new case study centred on bryophytes. Int Biodeter Biodegr 84:44-53

Bicer Simsir B, Griffin I, Palazzo-Bertholon B, Rainer L (2009) Lime-based injection grouts for the conservation of architectural surfaces. Rev Conserv 10:3-17

Biçer-Şimşir B, Rainer L (2013) Evaluation of lime-based hydraulic injection grouts for the conservation of architectural surfaces: a manual of laboratory and field test methods. Los Angeles: The Getty Conservation Institute

Blaeuer C, Rousset B (2014) Salt sources revisited. In Conference: SWBSS2014, $3^{\text {rd }}$ International Conference on Salt Weathering of Buildings and Stone Sculptures 14 - 16 October 2014

Borsoi G, Tavares M, Veiga R, Santos Silva A (2012) Microstructural and physical-mechanical analysis of the performance of nanostructured and other compatible consolidation products for historical renders. Mater Technol Mag (materili in Tehnologije) 46:93-97

Bourgès A, Vergès-Belmin V (2008) Comparison and optimization of five desalination systems on the inner walls of Saint Philibert Church in Dijon, France. Salt Weathering on Buildings and Stone Sculptures, 22-24 October 2008, The National Museum Copenhagen, Denmark, 29-40

Bruno L, Rugnini L, Spizzichino V, Caneve L, Canini A, Ellwood NTW (2019) Biodeterioration of Roman hypogea: the case study of the Catacombs of SS. Marcellino and Pietro (Rome, Italy). Ann Microbiol 69:1023-1032

Bruno L, Valle V (2017) Effect of white and monochromatic lights on cyanobacteria and biofilms from Roman Catacombs. Int Biodeter Biodegr 123:286-295

Burgio L (2021) Pigments, dyes and inks - their analysis on manuscripts, scrolls and papyri. Archaeol Anthropol Sci. https://doi. org/10.1007/s12520-021-01403-3

Camuffo D (2019) Microclimate for cultural heritage: measurement, risk assessment, conservation, restoration, and maintenance of indoor and outdoor monuments. Elsevier

Caneva G, Nugari MP, Salvadori O (2009) Plant biology for cultural heritage: biodeterioration and conservation; Getty Publications: Los Angeles. CA, USA

Caroselli M, Cavallo G, Felici A, Luppichini S, Nicoli G, Aliverti L, Jean G (2019) Gypsum in Ticinese stucco artworks of the 16-17th century: use, characterization, provenance and induced decay phenomena. J Archaeol Sci Rep 24:208-219

Caroselli M, Zumbühl S, Cavallo G, Radelet T (2020) Composition and techniques of the Ticinese stucco decorations from the 16th to the 17th century: results from the analysis of the materials. Herit Sci 8:1-20

Cather S (2006) Trans-technological methodology: setting performance criteria for conserving wall paintings. In Mazzeo R (ed) Far East Asian Mural Paintings: Diagnosis, Conservation and Restoration, pp. 89-95

Cather S (2003a) Aqueous extraction of soluble salts from porous materials: alternatives and contra-indications In Leitner $\mathrm{H}$, Laue S, Siedel H (eds) Mauersalze und Architekturoberfläche. pp. $167-172$

Cather S (2003b) Assessing causes and mechanisms of detrimental change to wall paintings. In Gowing R, Heritage A (eds) Conserving the painted past: developing approaches to wall painting conservation (Post-prints of an English Heritage Conference, 1999), London, pp. 64-74

Cather S (1991) The conservation of wall paintings: proceedings of a Symposium Organized by the Courtauld Institute of Art and the Getty Conservation Institute, London, July 13-16, 1987. Marina del Rey, CA: Getty Conservation Institute. http://hdl.handle.net/ 10020/gci_pubs/conserv_wall_paintings

Cavallo G, Riccardi MP (2021) Glass-based pigments in painting. Archaeol Anthropol Sci. (Forthcoming)

Charola AE, Wendler E (2015) An overview of the water-porous building materials interactions. Restoration of buildings and monuments

Dai S, Zhong Y (2019) Sacrificial protection for architectural heritage conservation and preliminary approaches to restore historic fairfaced brick façades in China. Built Herit 3:37-46

Dei L, Salvadori B (2006) Nanotechnology in cultural heritage conservation: nanometric slaked lime saves architectonic and artistic surfaces from decay. J Cultural Herit 7:110-115

DeLaine J (2021) Production, transport and on-site organisation of Roman mortars and plasters. Archaeol Anthropol Sci. https:// doi.org/10.1007/s12520-021-01401-5

Delgado Rodrigues J, Vale Anjos M, Charola AE (2011) Recolonization of marble sculptures in a garden environment. In Biocolonization of stone: control and preventive methods; Charola AE, McNamara C, Koestler RJ (eds), Smithsonian, Contributions to Museum Conservation; Smithsonian Institution Scholarly Press: Washington, DC, USA, 2011, pp. 71-85

Demas M (2002) Planning for conservation and management of archaeological sites. In Management planning for archaeological sites. Proceedings, pp. 27-54

Denninger E (1958) Die chemischen Vorgänge bei der Festigung von Wandmalereien mit sogenanntem Kalksinterwasser. Maltechnik 64:67-69

Domingo Sanz I, Chieli A (2021) Characterising the pigments and paints of prehistoric artists. Archaeol Anthropol Sci. https://doi. org/10.1007/s12520-021-01397-y.

Drdácký M, Slížková Z (2013) Enhanced affordable methods for assessing material characteristics and consolidation effects on stone and mortar. J Geophys Eng 10:064005

Egartner I, Sass O, Viles H, Dietzel M (2020) A multi proxy investigation of moisture, salt, and weathering dynamics on a historic urban boundary wall in Oxford, UK. Stud Conserv 65:172-188

Elsen J (2006) Microscopy of historic mortars-a review. Cement Con Res 36:1416-1424

EN 16572 (2015) Conservazione dei beni culturali - Glossario dei termini tecnici relativi alle malte di allettamento e gli intonaci utilizzati nel patrimonio culturale

Ergenç D, Fort R, Varas-Muriel MJ, Alvarez de Buergo M (2021) Mortars and plasters - how to characterise aerial mortars and plasters. Archaeol Anthropol Sci. https://doi.org/10.1007/ s12520-021-01398-x 
Ewa Glossary (2015) European illustrated glossary of conservation terms for wall paintings and architectural surfaces. Documentation. Michael Imhof Verlag, Petersberg, German

Feijoo J, Nóvoa XR, Rivas T, Ottosen LM (2018) Enhancing the efficiency of electrochemical desalination of stones: a proton pump approach. Mater Struct 51:100

Fidanza MR, Caneva G (2019) Natural biocides for the conservation of stone cultural heritage: A review. J Cult Herit 38:271-286

Flatt RJ, Girardet FJ (2000) Injectable slurries for the in situ conservation of pavementmosaics, in: Proceedings of the 9th International Congress on Deterioration andConservation of Stone, Venice, June 19-24 2000, Elsevier Science B.V., 2000, pp. 297-305

Franzoni E (2014) Rising damp removal from historical masonries: a still open challenge. Construct Build Mat 54:123-136

Franzoni E, Sassoni E, Graziani G (2015) Brushing, poultice or immersion? The role of the application technique on the performance of a novel hydroxyapatite-based consolidating treatment for limestone. J Cultural Herit 16:173-184

Gliozzo E (2021) Pigments - mercury-based red (cinnabar-vermilion) and white (calomel) and their degradation products. Archaeol Anthropol Sci. https://doi.org/10.1007/s12520-021-01402-4

Gliozzo E, Burgio L (2021) Pigments - Arsenic-based yellows and reds. Archaeol Anthropol Sci. https://doi.org/10.1007/ s12520-021-01431-z

Gliozzo E, Ionescu C (2021) Pigments - lead-based whites, reds, yellows and oranges and their alteration phases. Archaeol Anthropol Sci. https://doi.org/10.1007/s12520-021-01407-z

Gliozzo E, Pizzo A, La Russa MF (2021) Mortars, plasters and pigments - research questions and sampling criteria. Archaeol Anthropol Sci. https://doi.org/10.1007/s12520-021-01393-2

Griffin I (2004) Pozzolanas as additives for grouts: an investigation of their working properties and performance characteristics. Stud Conserv 49:23-34

Guillitte O (1995) Bioreceptivity: a new concept for building ecology studies. Sci Total Environ 167:215-220

Henriques FM (2005) Challenges and perspectives of replacement mortars in architectural conservation. In International workshop. Repair mortars for historic masonry, Rilem technical Committee, TU Delft, pp. 26-28

Hughes JJ (2017) Ineducable us: the applications and contexts of microscopy used for the characterisation of historic building materials. RILEM Tech Lett 2:136-144

Hughes JJ (2012) The role of mortar in masonry: an introduction to requirements for the design of repair mortars. Mater Struct 45:1287-1294

Hughes JJ, Válek J (2003) Mortars in historic buildings: a review of the conservation, technical and scientific literature. Historic Scotland.

ICOM-CC (2021) Terminology to characterize the conservation of tangible cultural heritage: http://www.icom-cc.org/242/about/termi nology-for-conservation/\#.YCELduhKg2w. Accessed 2021.02.01

Knapp CW, Christidis GE, Venieri D, Gounaki I, Gibney-Vamvakari J, Stillings M, Photos-Jones E (2021) The ecology and bioactivity of some Greco-Roman medicinal minerals: the case of Melos earth pigments. Archaeol Anthropol Sci. https://doi.org/10.1007/ s12520-021-01396-z

La Russa MF, Ruffolo SA (2021) Mortars and plasters - how to characterise mortars and plasters degradation. Archaeol Anthropol Sci. https://doi.org/10.1007/s12520-021-01405-1

La Russa MF, Macchia A, Ruffolo SA, De Leo F, Barberio M, Barone P, Crisci GM, Urzì C (2014) Testing the antibacterial activity of doped $\mathrm{TiO}_{2}$ for preventing biodeterioration of Cultural Heritage building materials. Int Biodeter Biodegr 96:87-96
Lancaster LC (2021) Mortars and plasters - how mortars were made. The Literary Sources. Archaeol Anthropol Sci. https://doi.org/ 10.1007/s12520-021-01395-0

Laurenzi Tabasso M, Simon S (2006) Testing methods and criteria for the selection/evaluation of products for the conservation of porous building materials. Stud Conserv 51:67-82

Liu Q, Zhang B, Shen Z, Lu H (2006) A crude protective film on historic stones and its artificial preparation through biomimetic synthesis. Appl Surf Sci 253:2625-2632

Lo Schiavo S, De Leo F, Urzì C (2020) Present and future perspectives for biocides and antifouling products for stone-built cultural heritage: ionic liquids as a challenging alternative. Appl Sci (Switzerland) 10(18):6568

Lubelli B, Van Hees RPJ, Brocken HJP (2004) Experimental research on hygroscopic behaviour of porous specimens contaminated with salts. Construct Build Mat 18:339-348

Lugli S, Caroselli M, Marchetti Dori S, Vandelli V, Marzani G, Segattini R, Weber J (2016) Building materials and degradation phenomena of the Finale Emilia Town Hall (Modena): an archaeometric study for the restoration project after the 2012 earthquake. Periodico Di Mineralogia 85:59-67

Mackay R (2019) Values-based management and the Burra Charter. Values in heritage management: emerging approaches and research directions, 110

Manoudis PN, Karapanagiotis I, Tsakalof A, Zuburtikudis I, Kolinkeovà $B$, Panayiotou C (2009) Superhydrophobic films for the protection of outdoor cultural heritage assets. Appl Phys A 97:351-360

Masi G, Sassoni E (2020) Comparison between ammonium phosphate and nanolimes for render consolidation. IOP Conference Series: Mat Sci Eng 949:012039

Mason R, Avrami E (2002) Heritage values and challenges of conservation planning. Management planning for archaeological sites. Manag Plan Archeol Sites Proc Greece 2000:13-26

Mastrotheodoros GP, Beltsios KG, Bassiakos Y (2021) Pigments iron-based red, yellow and brown ochres. Archaeol Anthropol Sci. (Forthcoming)

Matteini M (2008) Inorganic treatments for the consolidation and protection of stone artefacts. Conservation Science in Cultural Heritage 8:13-27. https://doi.org/10.6092/issn.1973-9494/1393

Matteini M, Rescic S, Fratini F, Botticelli G (2011) Ammonium phosphates as consolidating agents for carbonatic stone materials used in architecture and cultural heritage: preliminary research. Int J Archit Herit 5:717-736

Matteini M, Moles A, Giovannoni S (1994) Calcium oxalate as a protective mineral system for wall paintings: methodology and analyses. In: Fassina V, Ott H, Zezza F (eds) The conservation of monuments in the Mediterranean Basin. Proceedings of the 3rd International Symposium, pp. 155-162

Matteini M (1991) In Review: An assessment of Fiorentine methods of wall painting conservation based OD the use of mineral treatments. In Cather S (ed) The conservation of wall paintings, Los Angeles: The Getty Conservation Institute, pp 137-148

Michalski S (2008) Un modello fisico del processo di consolidamento, applicato principalmente ai dipinti. In L'attenzione alle superfici pittoriche: materiali e metodi per il consolidamento e metodi scientifici per valutarne l'efficacia: atti del congresso, Milano, 10-11 novembre 2006, pp. 27-50

Murat Z (2021) Wall paintings through the ages. The medieval period (Italy, 12th-15th century). Archaeol Anthropol Sci. https://doi. org/10.1007/s12520-021-01410-4

Nasraoui M, Nowik W, Lubelli B (2009) A comparative study of hygroscopic moisture content, electrical conductivity and ion chromatography for salt assessment in plasters of historical buildings. Construct Build Mat 23:1731-1735 
Olmi R, Bini M, Ignesti A, Priori S, Riminesi C, Felici A (2006) Diagnostics and monitoring of frescoes using evanescent-field dielectrometry. Measurement Science and Technology 17, art. no. 032, pp. 2281-2288

Osticioli I, Botticelli G, Matteini P, Siano S, Pini R, Matteini M (2017) Micro-Raman analysis on the combined use of ammonium oxalate and ammonium phosphate for the consolidation and protection of carbonate stone artifacts. J Raman Spect 48:966-971

Ottosen LM, Pedersen AJ, Rörig-Dalgaard I (2007) Salt-related problems in brick masonry and electrokinetic removal of salts. J Build Apprais 3:181-194

Palla F, Bruno M, Mercurio F, Tantillo A, Rotolo V (2020) Essential oils as natural biocides in conservation of cultural heritage. Molecules 25,730

Papayianni I, Válek J, Alvarez J, Bokan Bosiljkov V, Faria P, Ferrara L, Stukovnik P (2019) Testing properties governing the durability of lime-based repair mortars. In International Conference on Sustainable Materials, Systems and Structures (SMSS 2019) Durability, Monitoring and Repair of Structures 128, pp. 135-139

Pasian C, Piqué F, Jornet A, Cather S (2019) A 'sandwich' specimen preparation and testing procedure for the evaluation of non-structural injection grouts for the re-adhesion of historic plasters. Int J Architect Herit 15:455-466

Pasian C, Piqué F, Riminesi C, Jornet A (2017) How not to bother salts while grouting. In Proceedings of the 4th International Conference on Salt Weathering of Buildings and Stone Sculptures, edited by S. Laue, pp. 158- 167

Pasian C, Secco M, Piqué F, Artioli G, Rickerby S, Cather S (2018) Lime-based injection grouts with reduced water content: an assessment of the effects of the water- reducing agents ovalbumin and ethanol on the mineralogical evolution and properties of grouts. J Cult Herit 30:70-80

Pasian C, Martin de Fonjaudran C, Rava A (2020) Innovative waterreduced injection grouts for the stabilisation of wall paintings in the Hadi Rani Mahal, Nagaur, India: design, testing and implementation. Stud Conserv 65:244-250

Pel L, Sawdy A, Voronina V (2010) Physical principles and efficiency of salt extraction by poulticing. J Cult Herit 11:59-67

Pendleton JN, Gilmore BF (2015) The antimicrobial potential of ionic liquids: a source of chemical diversity for infection and biofilm control. Int J Antimicrob Agents 46:131-139

Pérez-Arantegui J (2021) Not only wall paintings - pigments for cosmetics. Archaeol Anthropol Sci. https://doi.org/10.1007/ s12520-021-01399-w

Petković J, Huinink HP, Pel L, Kopinga K, Van Hees RPJ (2007) Salt transport in plaster/substrate layers. Mat Struct 40:475-490

Pfendler S, Einhorn O, Karimi B, Bousta F, Cailhol D, Alaoui-Sosse L, Alaoui-Sosse B, Aleya L (2017) UV-C as an efficient means to combat biofilm formation in show caves: evidence from the La Glacière Cave (France) and laboratory experiments. Environ Sci Pollut Res 24:24611-24623

Pinna D (2017) Coping with biological growth on stone heritage objects. Methods, products, applications, and perspectives; Apple Academic Press: Oakville, ON, Canada, 2017

Piqué F, Wong L, Su B (2010) Methodology for the conservation of the wall paintings in cave 85 . In Proceedings of the Second International Conference on the Conservation of Grotto Sites, Mogao Grottoes, pp. 421-429

Porter JH, Pasian C, Secco M (2020) Diethyl oxalate-based microgrouts in calcium carbonate systems: formulation and application parameters. Int J Architect Herit 14:1106-1119

Randazzo L, Montana G, Castiglia A, La Russa MF (2020) Salt extraction from lime-based mortars: an experimental study using different poultice formulations. Construct Build Mat 255, pp. 119391

Reyes-Estebanez M, Ortega-Morales BO, Chan-Bacab M, Granados-Echegoyen C, Camacho-Chab JC, Pereañez-Sacarias JE,
Gaylarde C (2018) Antimicrobial engineered nanoparticles in the built cultural heritage context and their ecotoxicological impact on animals and plants: A brief review. Herit Sci. 6:52

Rickerby S, Shekede L, Fan Z, Tang W, Qiao H, Yang J, Piqué F (2010) development and testing of the grouting and soluble-salts reduction treatments of cave 85 wall paintings. In Conservation of Ancient Sites on the Silk Road, edited by N. Agnew, 471-479. Los Angeles: The Getty Conservation Institute

Riminesi C, Olmi R (2016) Localized microwave heating for controlling biodeteriogens on cultural heritage assets. Int J Conserv Sci 7:281-294

Rowe S, Rozeik C (2009) The uses of cyclododecane in conservation. Rev Conserv 9:17-31

Ruffolo SA, La Russa MF (2019) Nanostructured coatings for stone protection: an overview. Front Mater 6:147

Ruiz-Agudo E, Lubelli B, Sawdy A, Van Hees R, Price C, RodriguezNavarro C (2011) An integrated methodology for salt damage assessment and remediation: the case of San Jerónimo Monastery (Granada, Spain). Environmental Earth Sciences 63:1475-1486

Russo J, Luppichini S, Stefani C, Piqué F (2020) The study of Severini's wall paintings in Switzerland: how to manage heterogeneity of data and team members? In IOP Conference Series: Materials Science and Engineering 949, p. 012025

Salvadori M, Sbrolli C (2021) Wall paintings through the ages. The Roman period: Republic and early Empire. Archaeol Anthropol Sci. https://doi.org/10.1007/s12520-021-01411-3

Sassoni E, Franzoni E (2020) Lime and cement mortar consolidation by ammonium phosphate. Construct Build Mat 245:118409

Satish C (2013) History of architecture and ancient building materials in India Tech Book International. New Delhi, India, pp 315-334

Sawdy A, Heritage A, Pel L (2008) A review of salt transport in porous media, assessment methods and salt reduction treatments. Salt Weathering on Buildings and Stone Sculptures, 22-24 October 2008, The National Museum Copenhagen, Denmark, pp. 1-27

Sawdy A, Lubelli B, Voronina V, Pel L (2010) Optimizing the extraction of soluble salts from porous materials by poultices. Stud Conserv 55:26-40

Siegesmund S, Snethlage R (2011) Stone in architecture-properties, durability. Germany

Sierra-Fernández A, Gómez-Villalba LS, Rabanal ME Fort R (2017) New nanomaterials for applications in conservation and restoration of stony materials: a review. Mater Construct 67:e107

Silva M, Rosado T, Teixeira D, Candeias A, Caldeira AT (2017) Green mitigation strategy for cultural heritage: bacterial potential for biocide production. Environ Sci Pollut Res 24:4871-4881

Slížková Z, Drdácký M, Viani A (2015) Consolidation of weak lime mortars by means of saturated solution of calcium hydroxide or barium hydroxide. J Cultural Herit 16:452-460

Snethlage R, Wendler E (2000) Chemical conservation of stone structures. Ullmann's Encyclopedia of Industrial Chemistry

Snethlage R, Sterflinger K (2011) Stone conservation. In: Siegesmund S, Snethlage R (eds) Stone in architecture. Springer, Berlin, Heidelberg

Švarcová S, Hradil D, Hradilová J, Čermáková Z (2021) Pigments copper-based greens and blues. Archaeol Anthropol Sci. https:// doi.org/10.1007/s12520-021-01406-0

The Burra Charter (2013) The Australia ICOMOS Charter for places of cultural significance. Burwood: Australia ICOMOS. http://austr alia.icomos.org/wp-content/uploads/The-Burra-Charter-2013Adopted-31.10.2013.pdf.

Teutonico JM, McCaig I, Burns C, Ashurst J (1993) The Smeaton Project: factors affecting the properties of lime-based mortars. J Preserv Technol 25:32-49

Torraca G (2009) Lectures on materials science for architectural conservation. Los Angeles: Getty Conservation Institute 
Torraca G (1999) The scientist in conservation. Getty Conserv Inst Newslett Conserv 14:3

Tringham S, Rickerby S (2020) Challenges of conserving wall paintings: a 30-year perspective. Stud Conserv 65:327-332

Tringham S, Martin de Fonjaudran C, de Giorgio C, Cather S (2013) Passive and Remedial approaches to salt damage and biodeterioration of wall paintings and monuments in the Crypt of the Grand Masters, St John's Co-cathedral, Valletta. In: Wall Paintings in Crypts, Grottoes, Catacombs: Strategies for the Conservation of Coated Surfaces in Damp Environments, edited by Thomas Danzl, Matthias Exner, and Elisabeth Rüber-Schütte, pp. 85-96

UNI 1092 (2001) Beni culturali - Malte per elementi costruttivi e decorativi - Classificazione e terminologia

Urzì C, De Leo F (2007) Evaluation of the efficiency of water-repellent and biocide compounds against microbial colonization of mortars. Int Biodeter Biodegr 60:25-34

Válek J, Veiga R (2005) Characterisation of mechanical properties of historic mortars-testing of irregular samples. WIT Transact Built Environ 83, p. 10

Van Balen K, Papayianni I, Van Hees R, Binda L, Waldum A (2005) Introduction to requirements for and functions and properties of repair mortars. Mater Struct 38:781-785

Veiga R (2017) Air lime mortars: What else do we need to know to apply them in conservation and rehabilitation interventions? A review. Construct Build Mater 157:132-140

Veneranda M, Blanco-Zubiaguirre L, Roselli G, Di Girolami G, Castro KA, Madariaga JM (2018) Evaluating the exploitability of several essential oils constituents as a novel biological treatment against cultural heritage biocolonization. Microchem J 138:1-6

Vergès-Belmin V, Siedel H (2005) Desalination of masonries and monumental sculptures by poulticing: a review. Restor Build Mon 11:391-408

Vernez D, Wognin B, Tomicic C, Plateel G, Charrière N, Bruhin S (2010) Cyclododecane exposure in the field of conservation and restoration of art objects. Int Arch Occupat Environ Health 84:371-374

Viñas SM (2002) Contemporary theory of conservation. Stud Conserv 47:25-34

Vitti P (2021) Mortars and masonry - structural lime and gypsum mortars in antiquity and Middle Ages. Archaeol Anthropol Sci. https://doi.org/10.1007/s12520-021-01408-y

Welton T (2008) Ionic liquids: a brief history. Biophys Rev 10:691-706

Xiangna H, Xiao H, Bingjian Z (2016) Morphological studies of menthol as a temporary consolidant for urgent conservation in archaeological field. J Cult Herit 18:271-278

Yebra DM, Kiil S, Johansen KD (2004) Antifouling technology-past, present and future steps toward efficient and environmentally friendly antifouling coatings. Progr Org Coat 50:75-104

Zezza F (2010) Assessment of desalination mortars and poultices for historic masonry: the EU project "desalination"

Publisher's note Springer Nature remains neutral with regard to jurisdictional claims in published maps and institutional affiliations. 